UNIVERSIDADE DE SÃO PAULO

FACULDADE DE ODONTOLOGIA

\title{
AVALIAÇÃO “IN VITRO” DA MICROINFILTRAÇÃO NA INTERFACE DA PAREDE GENGIVAL DAS CAIXAS PROXIMAIS EM CAVIDADES \\ CLASSE II DE MOLARES DECÍDUOS, RESTAURADOS COM RESINA COMPOSTA AUTO E FOTOPOLIMERIZÁVEL
}

Dissertação apresentada à Faculdade de Odontologia da Universidade de São Paulo, para obtenção do Título de Mestre, no Curso de Pós-Graduação em Odontologia.

Área de Concentração em Odontopediatria.

São Paulo 
Data da defesa: 07 de Novembro de 1997.

\section{Banca Examinadora}

Julgamento

Prof. Dr. Adolpho Chelotti

Aprovado

Prof. Dr. Ronaldo Fazzi

Aprovado

Profa. Dra. Miriam Lacalle Turbino

Aprovado 
UNIVERSIDADE DE SÃO PAULO

FACULDADE DE ODONTOLOGIA

\section{AVALIAÇÃO “IN VITRO” DA MICROINFILTRAÇÃO NA INTERFACE DA PAREDE GENGIVAL DAS CAIXAS PROXIMAIS EM CAVIDADES CLASSE II DE MOLARES DECÍDUOS, RESTAURADOS COM RESINA COMPOSTA AUTO E FOTOPOLIMERIZÁVEL}

Dissertação apresentada à Faculdade de Odontologia da Universidade de São Paulo, para obtenção do Título de Mestre, no Curso de Pós-Graduação em Odontologia.

Área de Concentração em Odontopediatria.

Orientador: Prof. Dr. Adolpho Chelotti

Co-Orientadora: Prof ${ }^{a}$. Dr ${ }^{\mathrm{a}}$. Ana Lídia Ciamponi

São Paulo 
A meus pais,

Albano e Maria José,

Exemplos de amor e dedicação.

À minha esposa,

Por seu incentivo, carinho e paciência nos momentos mais dificeis.

A Dílson e Andréa,

Pessoas que aprendi a admirar e respeitar. 


\section{Prof. Dr. Antônio Carlos Guedes-Pinto}

"A oportunidade de uma convivência maior, brindou-me com a descoberta de qualidades antes imperceptiveis. Agradeço-lhe todo o apoio e atenção dispensadas, de modo que não tenho palavras para expressar a minha admiração e carinho à sua pessoa". 
Prof. Dr. Adolpho Chelotti

"Sua dedicação e disponibilidade sempre presentes, possibilitaram a conclusão deste trabalho. Além da orientação sempre precisa e segura, com que guiou meus passos, deu-me o prazer da sua amizade". 
Prof. Dr. Myaki Issáo

(in memorian)

"O Homem deve sempre considerar-se um estudante, procurando tornar-se mais competente e melhor".

(M. Chevreul) 


\section{AGRADECIMENTOS}

À Prof. Dra. Ana Lídia Ciamponi pela co-orientação deste trabalho, cujas sugestões contribuíram para a conclusão do mesmo.

Aos Professores Dra. Míriam Lacalle Turbino e Dr. Flávio Fernando Demarco pelas idéias, orientações e análise estatística.

Aos Professores da Disciplina de Odontopediatria da Faculdade de Odontologia da Universidade de São Paulo.

Aos amigos e colegas de Pós-Graduação em Odontopediatria da Faculdade de Odontologia da Universidade de São Paulo.

À Marlene Aparecida Pinotti, Júlio César Lima Faria e Marise Moraes de Paiva.

Ao CNPQ pela concessão da bolsa de estudos, possibilitando a realização do Curso de Pós-Graduação.

Ao técnico Arnaldo Pedroza da Silva pelo auxílio na parte laboratorial.

Às bibliotecárias Lucila Maria Giacomini, Marta Nosé Ferreira e Vânia Martins Bueno de Oliveira Funaro . 


\section{SUMÁRIO}

\section{RESUMO}

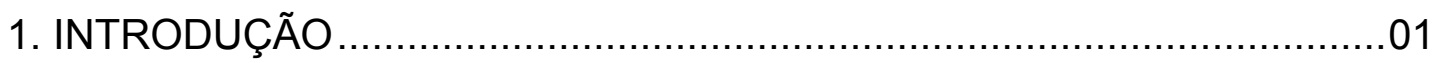

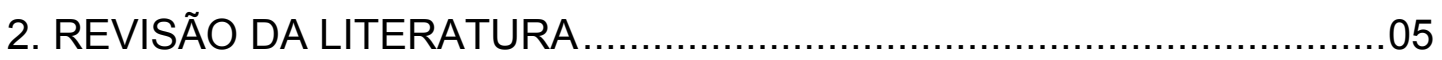

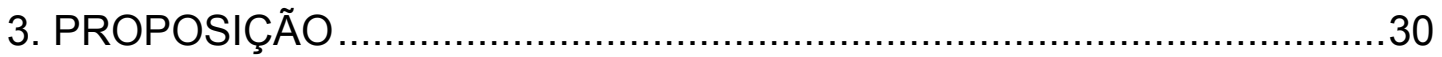

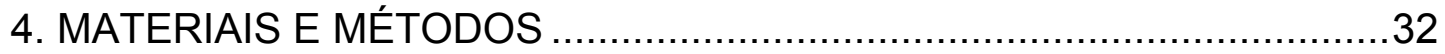

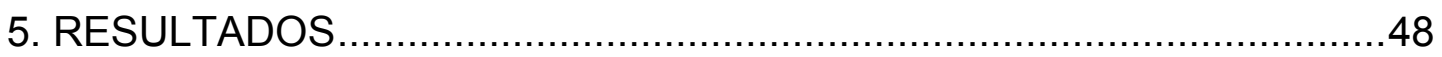

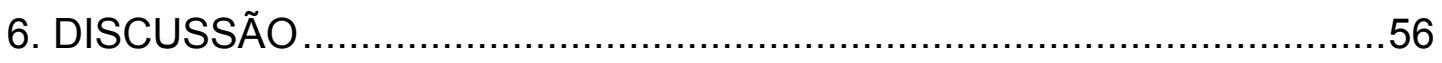

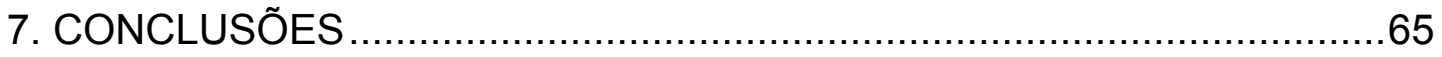

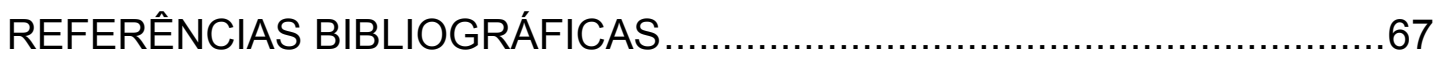

SUMMARY 


\section{LISTA DE FIGURAS}

Figura 1 - Máquina de Ciclagem Térmica

Figura 2 - Escala de avaliação (graus de infiltração): 0 = nenhuma infiltração; 1 = infiltração em esmalte; 2 = infiltração em 1/3 da parede gengival em dentina; 3 = infiltração em 2/3 da parede gengival em dentina; 4 = infiltração em toda a extensão da parede gengival 46

Figura 3 - Penetração do corante em amostra do grupo 1 49

Figura 4 - Penetração do corante em amostra do grupo 2 .50

Figura 5 - Penetração do corante em amostra do grupo 3 .50

Figura 6 - Penetração do corante em amostra do grupo 4 .51

Figura 7 - Interface resina composta autopolimerizável/fotopolimerizável ....55 
RESUMO 


\title{
RESUMO
}

\section{AVALIAÇÃO “IN VITRO” DA MICROINFILTRAÇÃO NA INTERFACE DA PAREDE GENGIVAL DAS CAIXAS PROXIMAIS EM CAVIDADES CLASSE II DE MOLARES DECÍDUOS, RESTAURADOS COM RESINA COMPOSTA AUTO E FOTOPOLIMERIZÁVEL}

\begin{abstract}
A finalidade deste estudo foi avaliar "in vitro" a microinfiltração marginal presente na interface da parede gengival de cavidades classe II em molares decíduos, restaurados com resina composta (auto e fotopolimerizável), com a utilização de uma solução corante. Os preparos cavitários apresentavam a parede gengival em esmalte, sendo restaurados segundo 4 diferentes técnicas: resina composta fotopolimerizável; resina composta autopolimerizável; técnica mista (resina composta auto e fotopolimerizável) e ionômero de vidro/resina composta. Em seguida, procedeu-se à ciclagem térmica $\left(5^{\circ} \mathrm{C}\right.$ e $55^{\circ} \mathrm{C}, 700$ ciclos), impermeabilização, imersão em solução corante e seccionamento. A avaliação quanto à microinfiltração, foi feita seguindo-se uma escala preestabelecida (graus de 0 a 4). Após a análise estatística dos resultados, concluiu-se que todos os grupos apresentaram microinfiltração, em graus variados, todavia os grupos que utilizaram a técnica mista e o ionômero/resina fotopolimerizável apresentaram os menores graus de infiltração, e que não se observou microinfiltração na interface resina composta autopolimerizável/fotopolimerizável.
\end{abstract}


1. INTRODUÇÃO 


\section{INTRODUÇÃO}

A Odontologia, seguindo os padrões estéticos vigentes, sempre buscou, através dos anos, o desenvolvimento de novos e melhores materiais levando a comunidade científica e as indústrias a aprimorarem materiais e técnicas restauradoras.

Dentre os materiais restauradores, a resina composta, provavelmente, foi o que apresentou uma maior evolução tecnológica. A introdução das resinas compostas fotopolimerizáveis foi um marco na dentística conservadora por apresentar maiores vantagens, entre as quais: maior tempo de trabalho, resistência e estabilidade de cor. Além de apresentar um menor grau de porosidade comparado às resinas autopolimerizáveis (Leinfelder \& Vann Jr., 1982).

Paralelo a este desenvolvimento, o progresso dos adesivos dentinários, seguido da introdução da técnica de condicionamento ácido total, aliado às crescentes controvérsias em relação ao uso do amálgama, possibilitaram o emprego das resinas compostas em dentes posteriores.

Mathewson et al. (1974) relatam uma alta proporção de falhas do amálgama em restaurações de dentes decíduos posteriores. Este fato, associado ao menor tempo de permanência na cavidade oral destes dentes, 
conseqüentemente uma maior expectativa de sucesso, ocasionou um maior emprego das resinas compostas em dentes decíduos, tanto em cavidades classe I quanto em cavidades classe II (Morris et al., 1979; Nelson et al., 1980; Garcia-Godoy, 1984; Oldenburg et al., 1985; Roberts et al., 1985; Imparato, 1996).

Uma resina composta indicada para dentes posteriores deve apresentar os seguintes requisitos: boa resistência ao desgaste oclusal e à abrasão, permitir uma adaptação precisa às margens cavitárias e uma vedação efetiva da restauração ao ingresso de fluidos orais que possam conter microorganismos, criando um ambiente propício para o desenvolvimento de cáries secundárias, adequada resistência à degradação à água ou outros solventes, deve ser radiopaca e as técnicas de aplicação e inserção devem ser simples e de fácil confecção (Ciamponi, 1992).

Apesar da grande melhoria nas características estruturais, alguns fatores indesejáveis continuam presentes, como a contração de polimerização e a alteração volumétrica provocadas pelas variações térmicas, podendo levar a um desajuste na interface dente-restauração, com conseqüente infiltração marginal (Vieira, 1991). A contração de polimerização varia de 2,0 a 3,2\% em volume (Lutz et al., 1986).

A microinfiltração marginal em restaurações de resina composta em cavidades classe II, pode ser um grande problema quando as margens cervicais estão localizadas abaixo da junção cemento-esmalte. Nesse caso, fendas poderão surgir entre a parede cervical da caixa proximal e a resina composta após a polimerização, o que poderá levar à fratura das margens 
da restauração, penetração bacteriana, desenvolvimento de cáries secundárias, descoloração marginal e hipersensibilidade (Marquez et al., 1990).

A adaptação marginal é influenciada pelos seguintes fatores:

preparo cavitário, (2) técnica de condicionamento ácido do esmalte,

uso de um adesivo, (4) técnica de inserção, (5) procedimentos de acabamento e (6) o próprio material restaurador (Hinoura et al., 1988).

A técnica mais favorável quando da restauração de cavidades classe II com resina composta fotopolimerizável é a técnica de inserção vertical (Donly et al., 1987; Imparato, 1996).

Bertolotti, 1991; Fusayama, 1992; Fusayama, 1993; Garberoglio et al., 1995, apresentam uma técnica restauradora cujo princípio é a associação entre a resina composta fotopolimerizável e a autopolimerizável, com o propósito de diminuir a contração de polimerização, quando este material for utilizado em cavidades classe II de dentes posteriores. Enfatizam que esta técnica proporciona a obtenção de uma melhor adaptação marginal e melhor qualidade da restauração.

Pelo exposto, o presente trabalho visa analisar a microinfiltração "in vitro" na interface da parede gengival das caixas proximais de cavidades classe II em molares decíduos, restaurados com resina composta auto e fotopolimerizável. 
2. REVISÃO DA LITERATURA 


\section{REVISÃO DA LITERATURA}

Mack (1970) foi o primeiro a relatar a utilização das resinas compostas para a restauração de molares decíduos. O autor usou a resina composta Adaptic (Jonhson \& Johnson Company) para restaurar todos os tipos de preparos em dentes decíduos (classes I a V), totalizando aproximadamente 2.700 superfícies dentárias restauradas após um período de 8 meses. Nesse intervalo de tempo, o autor encontrou falhas em somente 6 superfícies restauradas, as quais foram atribuídas a erros do operador e não à deficiência do material. Os resultados desse estudo levaram o autor a recomendar a utilização deste material para a restauração de dentes decíduos.

Avaliando o comportamento clínico, in vitro, de 48 restaurações de resina composta (Prestige - Lee Pharmaceuticals, South El Monte, CA) e 47 de amálgama (Aristalloy - Engelhardt Industries, Skokie, IL) em molares decíduos, Morris et al. (1979) encontraram, após 30 meses, 22\% de falhas nas restaurações de resina composta comparado com 6,9\%, nas restaurações de amálgama. Diante desse quadro, os autores não aconselharam a substituição de restaurações em amálgama por resina composta em molares decíduos. 
Nelson et al. (1979) realizaram um estudo no qual se avaliou o desempenho clínico de um amálgama (Dispersalloy) e duas resinas compostas (Adaptic e Adaptic Radiopaco) em 57 grupos de restaurações classe II em molares decíduos, de 50 pacientes. Após 24 meses, os autores relataram que ambas as resinas compostas apresentaram um comportamento clínico semelhante ao do amálgama.

Shey \& Oppenheim (1979) estudaram o comportamento clínico e radiográfico das resinas compostas Adaptic e Adaptic Radiopaco (Johnson \& Johnson Dental Products Co., East Windsor, NJ) em 38 cavidades classe I convencionais de molares decíduos, com bisel cavo-superficial, comparando as propriedades quanto à retenção, integridade marginal e alteração da coloração. Após 24 meses, as restaurações apresentaram um grau de retenção de $100 \%$, não mostrando descontinuidade marginal e as alterações na coloração foram mínimas para ambos os materiais.

Comparando o comportamento clínico de duas resinas compostas (Adaptic e Adaptic Radiopaco) e um amálgama rico em cobre (Dispersalloy) na restauração de preparos classe II convencionais, não biselados, em molares decíduos, Nelson et al. (1980) concluíram, após 24 meses, que não existiam diferenças significativas quanto à forma anatômica das restaurações de resina e amálgama. Todavia, ao final de 36 meses, as restaurações de resina composta apresentaram um maior desgaste comparado com as de amálgama. Quanto à adaptação marginal, os materiais não apresentaram diferenças significativas. Os autores concluíram que as resinas compostas poderiam ser indicadas como material restaurador 
para molares decíduos, desde que estes dentes permanecessem na cavidade oral por um período não superior a 3 anos.

Tonn et al. (1980) após avaliarem, por um período de 24 meses, o comportamento da resina composta Epoxydent (Lee Pharmaceutical Co., South El Monte, CA) e do amálgama Optaloy (L. D. Caulk Company, Milford, DE) para a restauração de cavidades classe II convencionais em molares decíduos, concluíram que as restaurações de resina composta, mesmo apresentando excelente estabilidade de cor e mínima descoloração marginal, demonstraram um maior desgaste oclusal e um maior número de cáries secundárias. Com base nesses resultados, os autores contraindicaram o uso dessa resina composta para restaurações classe II em molares decíduos.

Leifler \& Varpio (1981) analisaram o comportamento clínico de 91 restaurações de resina composta (Concise) classe II convencionais, biseladas, frente aos seguintes critérios da "California Dental Association": cor, forma anatômica e integridade marginal. Após 24 meses, relataram uma média de falhas de $34 \%$ das restaurações, as quais foram atribuídas a procedimentos clínicos errôneos como: não colocação do agente de união, manipulação do material e preparo cavitário conservador. Apesar desses resultados, os autores indicaram a utilização dessa resina composta como material restaurador para cavidades classe II em molares decíduos.

Analisando a utilização das resinas compostas em molares decíduos, Leinfelder \& Vann Jr. (1982) concluíram que os principais problemas associados ao uso desses materiais foram a perda dos contatos 
interproximais, espaços ou porosidades macroscópicas e sensibilidade pósoperatória.

Paquette et al. (1982) avaliaram o desempenho clínico das resinas compostas Profile (SS White) e VisioFil (ESPE) em dois tipos de preparos cavitários para cavidades classe I e II: modificado e convencional. amostra consistiu de 241 restaurações de 32 crianças com idades entre 4 e 8 anos, sendo 102 restaurações classe I e 139 classe II. Após 6 meses, não se encontrou alterações quanto à retenção, desgaste e descoloração em ambos os preparos. Os autores concluíram que o preparo cavitário modificado foi tão aceitável quanto o convencional e, quando utilizado em combinação com a resina composta, seria uma alternativa aceitável para molares decíduos.

Derkson et al. (1983) com o intuito de avaliar o desempenho clínico do amálgama Dispersalloy (Johnson \& Johnson Co.) e da resina composta Profile (S. S. White Co.) na restauração de cavidades classe I e II, executaram 225 restaurações em dentes decíduos e permanentes de 65 crianças. Após 24 meses, das 121 restaurações de resina composta avaliadas, 69 (56\%) não apresentaram defeitos, enquanto 90 (86,5\%) restaurações de amálgama encontravam-se nessas condições. Quando observado o desgaste oclusal, $25 \%$ das restaurações de resina composta apresentaram desgaste. Portanto, com base nesses resultados, os autores concluíram que o desempenho do amálgama foi superior ao da resina composta. 
Paquette et al. (1983) avaliaram, comparativamente, dois tipos de resinas compostas, uma autopolimerizável (Profile - S. S. White Dental Health Products, PA) e outra fotopolimerizável (Visio Fil - ESPE Co.; Valley Stram, N.Y.) como materiais restaurador de 240 cavidades classes I e II em molares decíduos. Dois preparos cavitários foram utilizados no estudo: convencional (controle), que foi o mesmo daquele usado nas restaurações de amálgama; b) modificado com bisel, o qual envolvia somente a remoção do tecido cariado. As margens de esmalte, em ambos os preparos, foram biseladas. Após 12 meses, os autores concluíram que os preparos modificados apresentaram um número maior de falhas, não servindo como substituto dos preparos convencionais, e que os materiais utilizados foram aceitáveis para o uso em preparos classe II convencionais, em molares decíduos, por pelo menos 1 ano.

Derkson et al. (1984) estudaram dois materiais restauradores, uma resina composta autopolimerizável (Profile) e um amálgama (Dispersalloy), em 202 preparos cavitários convencionais de dentes decíduos e permanentes. Após 36 meses, um total de 184 restaurações foram avaliadas. Os autores encontraram 46\% das restaurações de resina composta em bom estado, comparado com $80 \%$ das restaurações de amálgama nas mesmas condições. Vinte restaurações de resina composta apresentaram excessivo desgaste oclusal. Concluíram que o comportamento clínico das restaurações de resina composta foi inferior ao das restaurações de amálgama. 
Ao avaliar o comportamento clínico da resina composta P-10 autopolimerizável (Resin Bonded Ceramic, 3M, St. Paul, MN, EUA) na restauração de 115 preparos cavitários classe II convencionais, com bisel cavo-superficial, em molares decíduos de 50 crianças com idades entre 4 e 8 anos, Garcia-Godoy (1984) observou, após 12 meses, que o material apresentou um excelente comportamento clínico, sem perda aparente, e que apenas um dente apresentou ligeira descoloração marginal. Desta forma, relatou que preparos cavitários classe II convencionais em molares decíduos poderiam ser restaurados com esse material, por um período mínimo de 1 ano.

Dilley et al. (1985) observaram o tempo necessário para a colocação de 73 restaurações de resina composta, comparado-o com o da colocação de 60 restaurações de amálgama em molares decíduos e primeiros molares permanentes. Concluíram que as restaurações de resina composta necessitaram de um tempo $35 \%$ maior para sua colocação do que as restaurações de amálgama.

Observando o desempenho clínico de duas resinas compostas (F-70 e X-55) em três diferentes preparos de cavidades (preparo convencional, convencional com bisel e modificado) em 357 restaurações em dentes decíduos, sendo: 137 classe I, 188 classe II e 32 classe V; Oldenburg et al. (1985), ao final de 24 meses, não observaram diferenças significativas entre os três tipos de preparos cavitários ou entre os dois materiais, confirmando os resultados obtidos aos 12 meses (Oldenburg et al., 1984). As diferenças entre os desenhos cavitários e os materiais tornaram-se aparentes quando 
as falhas foram examinadas: os preparos modificados apresentaram $11,7 \%$ de falhas, os convencionais $4,5 \%$ e os convencionais com bisel $2,5 \%$. Os autores concluíram que os preparos convencionais biselados foram os mais recomendados para cavidades classe II em molares decíduos.

Roberts et al. (1985) compararam o desempenho clínico da resina composta Profile (S. S. White Dental Products International, PA) e do amálgama ASE (L. D. Caulk Co.; Milford, DE) em preparos classe II convencionais de molares decíduos. Foram analisadas 111 restaurações, sendo 61 de resina composta e 50 de amálgama, executadas em 37 crianças. Após 24 meses, 93 restaurações foram avaliadas (52 de resina composta e 41 de amálgama). 92\% das restaurações de resina composta apresentaram estabilidade de cor e $83 \%$ não apresentaram perda da forma anatômica. Quanto à adaptação marginal, 92\% das restaurações de resina composta apresentaram excelente adaptação, comparado com $83 \%$ das restaurações em amálgama. Os autores concluíram que as resinas compostas poderiam ser utilizadas com sucesso em restaurações de molares decíduos, particularmente em períodos próximos à esfoliação do referido dente.

Ao avaliarem o comportamento clínico da resina composta fotopolimerizável Ful-Fil em 96 cavidades classes I e II de molares decíduos, de 44 pacientes com média de idade de 5 anos e 8 meses, quanto à descoloração marginal, anatomia, adaptação e cáries secundárias, Tonn \& Ryge (1985) concluíram, após 24 meses, que das 76 restaurações avaliadas, 99\% apresentaram estabilidade de cor, $87 \%$ não mostraram 
descoloração nas margens cavo-superficiais e $86 \%$ não apresentaram alterações na forma anatômica, demonstrando que o material comportou-se bem quando utilizado em molares decíduos.

Varpio (1985) executou 91 restaurações classe II em molares decíduos, de crianças com média de idade de 7 anos e 4 meses, utilizando como material restaurador uma resina composta autopolimerizável (Concise Cap-Rynge, 3M Co., St. Paul, MN). Após 72 meses, observou que a percentagem das restaurações clinicamente boas decresceram com o passar dos anos. No primeiro ano, os resultados foram de $86 \% ; 72 \%$ para o segundo ano e $56 \%$ após o terceiro ano. Entre o quarto e sexto anos, a percentagem das restaurações classificadas como boas foi de $38 \%$. Apesar desses resultados, o autor concluiu que a resina composta, desde que sob condições favoráveis, foi um excelente material restaurador para dentes decíduos.

Estudando o comportamento de duas resinas compostas (P-10 e FulFil), colocadas em cavidades classe I e II de dentes decíduos e permanentes, Derkson \& Richardson (1986) constataram, após 36 meses, que das 72 restaurações avaliadas, $80 \%$ das mesmas apresentaram padrão Alfa para a adaptação marginal e 93\%, para a estabilidade de cor. Concluíram que as restaurações foram bem sucedidas.

Donly \& Jensen (1986) avaliaram "in vitro" a tensão produzida pela contração de polimerização do adesivo Scotchbond e da resina composta P-30 (3M Dental Products: St. Paul, MN) em 10 cavidades classe II de molares decíduos, restaurados com 3 diferentes técnicas: a) condensação e 
polimerização da resina composta em porção única, b) condensação e polimerização em camadas gengivo-oclusais e c) condensação e polimerização em camadas vestíbulo-linguais. Quando do preparo cavitário, confeccionou-se um preparo MOD, com um bisel de $0,5 \mathrm{~mm}$ em esmalte. Cada dente foi restaurado usando todas as 3 técnicas. Os resultados encontrados demonstraram que a técnica restauradora que provocou uma maior tensão foi a da porção única, provavelmente em virtude do maior volume de resina composta quando polimerizado. Os melhores resultados foram encontrados com a técnica que utilizou incrementos vestíbulo-linguais, por apresentar menor volume do material.

Holan et al. (1986) estudaram "in vitro" a microinfiltração na interface de restaurações classe II de dentes decíduos, com resina composta P-10, através da penetração de um corante, utilizando o Scotchbond como adesivo. Foram utilizados 48 molares decíduos, nos quais confeccionou-se um preparo classe II convencional, com bisel cavo-superficial. Os dentes foram divididos em dois grupos: A (experimental), no qual o Scotchbond (Dental Products, 3M, St. Paul, MN) foi usado como agente de união do esmalte e da dentina e B (controle), que apresentava a dentina recoberta por Dycal (L. D. Caulk Company, Milford, DL), utilizando o agente de união da resina composta Concise (Dental Products, 3M, St. Paul, MN) somente para o esmalte. Os dentes foram armazenados à temperatura ambiente durante dez dias e posteriormente termociclados $\left(4^{\circ} \mathrm{C} \pm 2\right.$ e $60^{\circ} \mathrm{C} \pm 2$, com dois banhos em cada etapa). Observou-se a penetração do corante nas margens cervicais em $62,5 \%$ das restaurações do grupo A e $16,7 \%$ no grupo B. 
Portanto, os resultados demonstraram que o adesivo Scotchbond não foi efetivo quando utilizado para prevenir a infiltração marginal, quer na região oclusal quer nas margens cervicais, de restaurações de classe II de resina composta em molares decíduos.

Avaliando duas resinas compostas (F-70 e X-55) colocadas em 3 diferentes preparos cavitários (convencional, convencional com bisel e modificado) em molares decíduos, Vann Jr. et al. (1986a) executaram 357 restaurações em 50 crianças com idades entre 4 e 8 anos. Ao final de 36 meses, $213(59,6 \%)$ restaurações foram avaliadas, encontrando-se um total de 32 falhas $(8,9 \%)$, distribuídas da seguinte forma: preparo convencional $4,8 \%$; convencional com bisel $4,5 \%$ e modificado $15,3 \%$. Os autores concluíram que ambos os materiais tiveram um bom desempenho após 36 meses, quando se utilizou o preparo convencional ou convencional com bisel.

Vann Jr. et al. (1986b) avaliaram, qualitativa e quantitativamente, o desgaste oclusal apresentado em 184 restaurações de resina composta (Ful-Fil - L. D. Caulk Co., Division of Dentsply International: Milford, DE) executadas em molares decíduos de 51 pacientes, com idades entre 4 e 8 anos. Após 24 meses, e 148 restaurações avaliadas, os resultados qualitativos foram excelentes, enquanto que a avaliação quantitativa apresentou um valor de desgaste total de $93 \mu \mathrm{m}$, sendo: $40 \mu \mathrm{m}$ nos 6 primeiros meses, $32 \mu \mathrm{m}$ entre 6 e 12 meses, e $21 \mu \mathrm{m}$ entre 12 e 24 meses. Os autores concluíram que estes valores encontravam-se de acordo com as 
normas da American Dental Association - ADA, cujo padrão requer um desgaste máximo de $50 \mu \mathrm{m} / \mathrm{ano}$.

Dilley et al. (1987) compararam a efetividade clínica do amálgama Sybralloy e da resina composta Caulk $\mathrm{H}-120$ utilizados como material restaurador de 335 cavidades classe I e II de molares decíduos e permanentes. Após 36 meses, observaram que para as restaurações classe II de molares decíduos, a integridade marginal foi de $92,9 \%$ para as restaurações de resina composta e $75 \%$ para as de amálgama. 58,7\% das restaurações de resina composta apresentaram desgaste. Com base nos resultados, os autores concluíram que as restaurações de resina composta apresentaram um desempenho superior quando comparado com as de amálgama em molares decíduos.

Donly et al. (1987) avaliaram, "in vivo", a tensão produzida pela contração de polimerização das resinas compostas em cavidades classe II de dentes decíduos através da comparação de 3 diferentes técnicas restauradoras. Foram utilizados 30 molares decíduos, nos quais confeccionou-se um preparo classe II convencional. As técnicas foram as mesmas utilizadas por Donly \& Jensen, em 1986, a saber: técnica de colocação e polimerização em porção única; colocação e polimerização em incrementos gengivo-oclusais e colocação e polimerização em incrementos vestíbulo-linguais. Os resultados demonstraram uma flexibilidade da cúspide de 19,7 mícrons para a técnica de porção única; 14,7 mícrons para a técnica de incrementos gengivo-oclusais e 5,2 mícrons para a técnica de incrementos vestíbulo-linguais. Os autores sugeriram a colocação e 
polimerização em camadas vestíbulo-linguais de resina composta, quando da sua utilização como material restaurador para cavidades classe II em dentes decíduos.

Dando prosseguimento ao estudo iniciado em 1983, avaliando 3 tipos de preparos cavitários para restaurações com resina composta em molares decíduos (preparo convencional, convencional com bisel e modificado), Oldenburg et al. (1987b) obtiveram os seguintes resultados após 48 meses: $8,2 \%$ de falhas para os preparos convencionais; $6,7 \%$ para os preparos convencionais com bisel e $17,8 \%$ para os preparos modificados. Os autores, confirmando os resultados obtidos aos 24 meses, concluíram que o preparo convencional com bisel é o mais recomendado para dentes decíduos posteriores, salientando o fato de que as falhas encontradas poderiam estar mais relacionadas com a técnica de restauração do que propriamente com o comportamento clínico do material.

Richardson \& Derkson (1987) avaliando comparativamente o desempenho das resinas compostas Ful-Fil e P-10 na restauração de 237 preparos classe II modificados em dentes decíduos e permanentes, de 102 pacientes, concluíram, após 48 meses, que das 66 restaurações examinadas (27 restaurações com Ful-Fil e 39 com P-10), a perda do material e a descoloração marginal foram menos freqüentes na resina composta $\mathrm{P}-10$ (89\% e $85 \%$, respectivamente) do que na resina composta Ful-Fil ( $77 \%$ e $55 \%$, respectivamente). Entretanto, ambos os materiais apresentaram resultados clínicos de acordo com os critérios da ADA. 
Estudando "in vitro" a flexibilidade das cúspides, em cavidades classe II de 12 molares decíduos, de 3 diferentes materiais restauradores: amálgama (Premalloy - Espe - Premier Sales Co.; Norristown, PA); cimento de ionômero de vidro com prata (Ketac Silver - Espe - Premier Sales Co.; Norristown, PA) e resina composta fotopolimerizável (P-30 - 3M Dental Products, St. Paul, MN), Donly et al. (1988) constataram que as restaurações de resina composta apresentaram uma resistência média de $75 \%$ da resistência original; o cimento de ionômero de vidro com prata $52 \%$ e o amálgama $34 \%$ de resistência. Com base nesses resultados, os autores concluíram que as restaurações de resina composta proporcionaram menor flexibilidade das cúspides quando comparadas às de cimento de ionômero de vidro com prata e às de amálgama.

Fisbein et al. (1988) determinaram o efeito da utilização dos adesivos dentinários Scotchbond VLC e Enamel Bond (3M, Dental Products, St. Paul, MN) e de 2 técnicas restauradoras (incremental e porção única) sobre a microinfiltração em restaurações classe II de resina composta de 62 molares decíduos. Os dentes foram divididos em 4 grupos, com margens gengivais terminadas em esmalte. Os grupos A e B receberam aplicação do Scotchbond VLC no esmalte e dentina, enquanto os grupos C e D, cujo agente de união foi o Enamel Bond, apenas nas margens de esmalte. Quanto à técnica restauradora, os grupos A e C tiveram a resina composta colocada e condensada em 3 camadas, com a polimerização se dando separadamente. Por sua vez, os grupos B e D também apresentaram a colocação e condensação do material em 3 camadas, todavia 
fotopolimerizadas em uma única vez. Como resultados, após a ciclagem térmica de 100 ciclos $\left(4 \pm 2^{\circ} \mathrm{C}\right.$ e $\left.60 \pm 2^{\circ} \mathrm{C}\right)$, os autores observaram que a infiltração foi menor nas margens oclusais do que nas cervicais. Quando da comparação dos 2 adesivos, as diferenças não foram significativas. A técnica restauradora que apresentou menor infiltração marginal foi a técnica incremental, independente do adesivo utilizado, quando comparada à técnica de porção única. Os autores concluíram que nenhuma das técnicas restauradoras estudadas forneceu um perfeito selamento das margens.

Avaliando o comportamento clínico da resina composta Ful-Fil D. Caulk/Dentsply) colocada em 96 cavidades classes I e II de molares decíduos, de 44 crianças com idades entre 4 e 8 anos, Tonn \& Ryge (1988) observaram, ao final de 48 meses, que $100 \%$ das restaurações apresentaram estabilidade de cor e $86 \%$ não apresentaram descoloração marginal. O desgaste médio encontrado foi de $125 \mu \mathrm{m}$, estando dentro das especificações da ADA. 98\% das restaurações não apresentaram cáries recorrentes. Frente a esses resultados, e diante da boa radiopacidade do material, os autores concluíram que a resina composta Ful-Fil satisfazia os requisitos exigidos pela $A D A$, servindo como material restaurador para cavidades classe I e II em molares decíduos, e que as resinas compostas pareciam se desgastar numa proporção mais semelhante ao desgaste fisiológico que ocorre nos dentes decíduos.

Vann Jr. et al. (1988) compararam os resultados obtidos em 2 diferentes estudos, quando da avaliação quantitativa do desgaste apresentado pelas restaurações de resina composta executadas em molares 
decíduos, bem como, compararam esses resultados com aqueles obtidos utilizando-se os critérios U. S. P. H. S. (United States Public Health Service Serviço de Saúde Pública dos Estados Unidos). No total, 212 restaurações classes I e II, executadas em 86 pacientes, foram analisadas. Os resultados mostraram que, após 36 meses, o valor e a quantidade do desgaste apresentado foram semelhantes àqueles observados em dentes permanentes, e que os critérios de avaliação U. S. P. H. S. foram insensíveis para a detecção inicial do desgaste em molares decíduos.

Wendell \& Vann Jr. (1988) avaliaram direta e indiretamente o desgaste oclusal sofrido pelas restaurações de resina composta em molares decíduos comparado ao desgaste observado nos molares permanentes. As comparações indiretas foram feitas a partir dos dados de 4 diferentes trabalhos. Os resultados mostraram, após 24 meses, que o desgaste para os molares decíduos foi de $93 \mu \mathrm{m}$ comparado com $86 \mu \mathrm{m}, 104 \mu \mathrm{m}$ e $119 \mu \mathrm{m}$ para os molares permanentes. A amostra para a comparação direta consistiu de 92 restaurações classes I e II nos molares decíduos e 95 restaurações classe I nos molares permanentes. Ao final de 24 meses, os molares decíduos apresentaram $2 \mu \mathrm{m}$ a mais de desgaste do que os dentes permanentes. De posse desses resultados, os autores concluíram que o desgaste encontrado nas restaurações com resina composta foi semelhante em ambos os dentes, decíduos e permanentes.

Eildelman et al. (1989) avaliaram clínica e radiograficamente 60 restaurações de resina composta classe II em molares decíduos, de 22 crianças entre 8 e 12 anos, executadas com a técnica de inserção única e 
incremental. Após 12 meses, os autores observaram que houve um bom desempenho da resina composta na superfície oclusal e que as margens cervicais da caixa proximal foram a maior fonte de problemas das restaurações classe II com resina composta. Os autores concluíram que não existiram diferenças nos resultados quanto às técnicas de inserção do material e que a avaliação das margens e superfícies proximais é primordial, antes de se recomendar a utilização rotineira desse material na restauração de cavidades classe II. Os resultados encontrados, após 24 meses, foram semelhantes, ressaltando-se a importância do desenvolvimento de técnicas restauradoras mais precisas para a utilização da resina composta em preparos classe II, uma vez que ambas as técnicas, inserção única e incremental, não foram capazes de permitir uma boa adaptação marginal, principalmente nas margens cervicais da caixa proximal do preparo (Fuks et al., 1990b).

Guelmann et al. (1989) avaliaram "in vitro" a infiltração marginal ocorrida em 58 restaurações classe II de molares decíduos, utilizando 3 diferentes técnicas restauradoras: a) resina composta com base de ionômero, b) ionômero cerment/resina composta e c) ionômero cerment, através de radiografias e microscopia eletrônica de varredura. Quando da avaliação radiográfica, $94 \%$ das margens com ionômero cerment Ketac Silver (ESPE, Seefeld/Oberbay, W. Germany) mostraram excelente adaptação, associado ou não à resina composta. Ao se avaliar a resina composta P-30 (3M, Dental Products, St. Paul. MN), 75\% das margens mostraram boa adaptação. A avaliação ao microscópio eletrônico 
demonstrou que uma grande deterioração das margens cervicais foi observada em todos os grupos, sem diferenças estatísticas entre o Ketac Silver e a resina composta P-30. Diante desses resultados, os autores concluíram que o Ketac Silver, associado ou não à resina composta, não preveniu a microinfiltração quando utilizado em restaurações classe II.

Avaliando comparativamente "in vitro" 2 tipos de preparos cavitários classe II (convencional e modificado) e 2 bases restauradoras para resina composta: ionômero de vidro fotopolimerizável (Ketac Bond, ESPE - Premier Sales Co., Norristown, PA) e hidróxido de cálcio (Dycal; L. D. Caulk Co., Milford, DE), Donly et al. (1990) utilizaram 28 molares (14 decíduos e 14 permanentes), hígidos, na execução do estudo. Quatorze dentes

decíduos e 7 permanentes) receberam preparos cavitários classe II modificados, colocando-se em um grupo uma base de cimento de ionômero de vidro e no outro, hidróxido de cálcio. Os 14 dentes restantes, receberam preparos cavitários classe II convencionais, colocando-se as bases como nos grupos anteriores. Os resultados encontrados demonstraram que as restaurações convencionais e modificadas que utilizaram uma base de ionômero apresentaram menor microinfiltração marginal quando comparadas com as amostras que utilizaram como base o hidróxido de cálcio.

Fuks et al. (1990a) avaliaram a microinfiltração presente ao redor de restaurações classe II com resina composta Herculite (Kerr Co., Romulus, Michigan 48177 USA) em 13 molares decíduos, utilizando 2 técnicas restauradoras (inserção única e incremental). Os resultados encontrados, após 12 meses, não mostraram diferenças entre as técnicas, com as 
margens oclusais da maioria dos dentes (85\%) não apresentando infiltração. Todavia, as margens cervicais das caixas proximais de todas as restaurações apresentaram microinfiltração. Portanto, os autores concluíram que a técnica de inserção incremental (sentido gengivo-oclusal) não foi capaz de eliminar a microinfiltração nas margens cervicais de restaurações classe II com resina composta.

Ao estudarem a microinfiltração em 60 restaurações classe II de dentes decíduos, Marquez et al. (1990) utilizaram como materiais restauradores amálgama (Luxalloy sem gama 2) e resina composta (Heliomolar - Vivadent). A amostra foi dividida em dois grupos de 30 dentes cada, com o grupo $A$ recebendo o amálgama e o $B$, resina composta. Os resultados, após 18 meses, demonstraram que o amálgama apresentou um melhor desempenho do que a resina composta. Os autores relataram que os maiores problemas encontrados com a resina composta se referiam à contração de polimerização e a excessiva deterioração do material, recomendando sua utilização em situações em que o tempo de vida útil do dente decíduo não ultrapasse 3 anos, e que a técnica restauradora utilizada nesses casos seja a de inserção incremental.

Nicole Filho et al. (1990) avaliaram a infiltração marginal "in vivo" em 28 restaurações classe II de molares decíduos, de 18 crianças, cujos dentes encontravam-se próximos à época de esfoliação. Utilizou-se como material restaurador a resina composta fotopolimerizável Estilux Posterior (Kulzer: Produtos Odontológicos Ltda.) associada à adesivo de dentina (Dentin Adhesive, Kulzer: Produtos Odontológicos). Os resultados apresentados 
demonstraram que todos os dentes apresentaram microinfiltração em diferentes graus. Os autores não recomendaram a utilização da resina composta como substituta do amálgama em restaurações classe II de dentes decíduos, mas somente em cavidades classes I, III e V, ou quando a estética estivesse comprometida.

Varpio et al. (1990) estudaram o comportamento clínico da resina composta Concise (Cap-C-Rynge, 3M, St. Paul, MN, USA), colocada em 91 restaurações classe II de molares decíduos, quanto à adaptação marginal, cárie secundária e reação pulpar. Após o preparo cavitário, as cavidades foram lavadas com solução de clorexidina a $0,1 \%$, colocando-se, em seguida, uma base de poliestireno. As margens de esmalte foram condicionadas e a resina composta autopolimerizável Concise Cap-C-Rynge colocada em porção única, sem agente de união. Após 72 meses, observaram que $75 \%$ das restaurações não apresentaram um selamento satisfatório, com $44 \%$ das amostras apresentando necrose pulpar. Desta forma, demonstrou-se que fendas e descoloração marginal deveriam ser consideradas como problemas graves, podendo levar a complicações pulpares.

Barr-Agholme et al. (1991) avaliaram comparativamente o comportamento clínico do amálgama (Dispersalloy, Lee Pharmaceuticals Co., South El Monte, CS) e da resina composta (P-30, 3M) em 119 restaurações classe II em molares decíduos, de 43 crianças. Após 24 meses, e 86 restaurações examinadas, encontraram que $88 \%$ das restaurações de resina composta foram classificadas como Alfa ou Bravo, 
comparado com $68 \%$ das restaurações em amálgama. Com relação a adaptação marginal, $94 \%$ das restaurações de resina composta foram classificadas como Alfa ou Bravo, comparado com $68 \%$ dos amálgamas. Concluíram, portanto, que as resinas compostas foram um material restaurador aceitável para cavidades classe II em dentes decíduos.

Bertolotti (1991) descreveu uma técnica para a restauração de cavidades classe II em dentes posteriores utilizando resina composta, cujo princípio baseava-se na combinação da resina composta autopolimerizável com a fotopolimerizável, como meio de se reduzir a contração de polimerização das mesmas, a fim de se obter uma melhor qualidade e adaptação marginal da restauração. Após o condicionamento ácido e aplicação do sistema adesivo, o autor sugeriu a colocação de uma pequena camada de resina composta autopolimerizável, de aproximadamente $1 \mathrm{~mm}$, na porção cervical, seguida de uma pequena camada de resina fotopolimerizável, com a finalidade de promover uma leve condensação do material colocado na primeira camada. Após o endurecimento da primeira camada, fotopolimerizava-se a segunda camada, preenchendo-se o restante da cavidade com resina composta fotopolimerizável. O autor destacou como fatores favoráveis uma melhor adaptação marginal, menor sensibilidade pós-operatória, redução do tempo de trabalho em decorrência de uma maior facilidade de colocação da matriz e melhor obtenção dos contatos proximais.

Vieira (1991) avaliou "in vitro" a microinfiltração marginal ocorrida na parede cervical de cavidades classe II de molares decíduos restaurados com 
resina composta fotopolimerizável. Foram utilizados 32 dentes, divididos em dois grupos de 16, de acordo com a técnica de inserção utilizada (técnica "convencional" e técnica vertical). Após a conclusão das restaurações, obteve-se réplicas das faces mesiais e distais de 16 dentes, antes e após a ciclagem térmica, a fim de se observar qualitativamente a interface dente/restauração ao microscópio eletrônico de varredura. Os dentes restantes, após a ciclagem térmica e imersão em solução corante, foram seccionados e analisados quantitativamente quanto à microinfiltração. Como resultados, o autor encontrou que não existiram diferenças estatisticamente significantes quanto à infiltração entre as 2 técnicas restauradoras. A utilização do cimento de ionômero de vidro como material forrador diminuiu significativamente a microinfiltração marginal quando comparado àquelas cavidades em que o material forrador não foi utilizado.

Ciamponi (1992) avaliou o desempenho clínico da resina composta Adaptic II na restauração de 45 cavidades classe II em molares decíduos, de 22 crianças com idades entre 4 e 8 anos. Como variáveis foram utilizados o emprego do bisel e os grupos de dentes restaurados. Após 24 meses, os resultados encontrados demonstraram que em relação à estabilidade de cor, $72,4 \%$ das restaurações tiveram padrão Alfa na avaliação direta e 40,9\% na indireta. Quanto ao desgaste, encontrou-se que 75,9\% das restaurações apresentaram desgaste na avaliação direta, representando $87,6 \mu \mathrm{m}$ na indireta (observada nos modelos em gesso). Quanto à integridade marginal, observou-se que a mesma foi influenciada pelo bisel cavo-superficial, e que 
a presença de cáries secundárias apresentou uma incidência de 6,4\% nos dentes restaurados.

Avaliando "in vivo" o efeito da impregnação da margem cervical com adesivo de esmalte autopolimerizável (Concise - 3M Dental Products) sobre a microinfiltração marginal em 60 restaurações classe II de resina composta (P-30, 3M) em molares decíduos, Holan et al. (1992) observaram, após 18 meses, que das 52 restaurações avaliadas radiograficamente, apenas $19 \%$ das mesmas apresentaram defeitos de radioluscência nas margens cervicais. Apesar dos excelentes resultados clínicos e radiográficos, os autores concluíram que as restaurações de resina composta deveriam ser cuidadosamente avaliadas quanto à presença de cáries secundárias nas margens cervicais e alterações pulpares.

Ao avaliarem comparativamente a longevidade clínica de 3 diferentes materiais restauradores: amálgama (ANA 2000, ANA, Sweden), resina composta (Oclusin, ICI, Great Britain) e cimento de ionômero de vidro (Chemfil II, Kerr, USA) utilizados em 75 restaurações classe II de molares decíduos, Ostlund et al. (1992) verificaram, após 36 meses, que 92\% das restaurações de amálgama foram classificadas como Alfa ou Bravo; as de resina corresponderam a $84 \%$ e as de ionômero a $40 \%$. Com base nesses resultados, os autores concluíram que tanto o amálgama quanto a resina composta apresentaram um bom desempenho, enquanto o ionômero necessitava de um maior tempo de estudo, a fim de se adaptar as características do material ao formato da cavidade. 
Sperb et al. (1993) estudaram "in vitro" o efeito do condicionamento ácido da base de cimento de ionômero de vidro (Vidrion F, SS White) na microinfiltração de restaurações classe II de resina composta (APH, Dentsply) em molares decíduos. A amostra consistiu de 20 dentes, divididos em 2 grupos: 1) base de ionômero condicionada por 30 segundos (experimental) e 2) base não condicionada (controle). Os resultados mostraram que o grupo no qual a base não foi condicionada (controle) apresentou os menores níveis de microinfiltração.

Reid et al. (1994) avaliaram comparativamente, "in vitro", a capacidade de selamento do ionômero de vidro, nas técnicas aberta e fechada, das margens cavo-superficiais de cavidades classe II, restauradas com resina composta, em 80 molares decíduos, os quais foram divididos em 4 grupos de 20 dentes cada. Nos grupos 1 e 2, as margens cavitárias terminaram em esmalte, enquanto nos grupos 3 e 4, em cemento/dentina. Os resultados demonstraram que a técnica aberta (ionômero de vidro na junção amelo-dentinária) mostrou menor microinfiltração comparada à técnica fechada (ionômero de vidro colocado $1 \mathrm{~mm}$ aquém da junção amelodentinária), sendo aceitável sua utilização em molares decíduos.

Estudando a microinfiltração em restaurações classe II de molares decíduos, Miranda Jr. \& Bussadori (1995) utilizaram como materiais restauradores: resina composta fotopolimerizável (Z-100, 3M); resina composta autopolimerizável $(\mathrm{P}-10,3 \mathrm{M})$ e os ionômeros de vidro Vitremer (fotopolimerizável, 3M) e Shofu (autopolimerizável). As amostras foram divididas em 4 grupos: grupo 1: resina Z-100/adesivo; 
grupo 2: resina P-10/adesivo/Z-100; grupo 3: Vitremer/adesivo/Z-100 e grupo 4: Shofu/adesivo/Z-100. Os dentes foram submetidos à ciclagem térmica (700 ciclos, $\left.5 / 55^{\circ} \mathrm{C}\right)$ e mecânica $(8,0 \mathrm{kgf} / 100.000$ ciclos $)$, corados e seccionados. Os resultados demonstraram que o grupo 4 apresentou o menor grau de infiltração quando comparado com os outros grupos.

Imparato (1996) avaliou "in vivo" a microinfiltração ocorrida em cavidades classe II de molares decíduos, restaurados com resina composta Prisma APH (Dentsply Ind. e. Com. Ltda - Petrópolis - RJ) utilizando 4 diferentes técnicas de inserção (vertical, pré-polimerizada, horizontal e única). Foram utilizados 12 molares decíduos hígidos, próximos à época de esfoliação, em crianças com idade entre 8 e 12 anos. Confeccionou-se 2 cavidades ocluso-proximais (OM e OD), totalizando 24 cavidades, restauradas de acordo com as 4 técnicas de inserção. Uma semana após a conclusão das restaurações, os dentes foram extraídos, ciclados, impermeabilizados, corados e seccionados. O autor concluiu que todas as técnicas apresentaram microinfiltração em diferentes graus, com a técnica vertical mostrando-se superior às demais, não existindo diferenças significativas entre as outras (pré-polimerizada, horizontal e única) em relação à microinfiltração. 
3.PROPOSIÇÃO 


\section{PROPOSIÇÃO}

Com o exposto na revisão da literatura, propomo-nos a:

1) Estudar a infiltração marginal na interface da parede gengival da caixa proximal em cavidades classe II, de molares decíduos, restaurados:

1.1 com resina composta fotopolimerizável;

1.2 com resina composta autopolimerizável;

1.3 com uma técnica mista, ou seja, uma camada de resina composta autopolimerizável junto a essa parede, seguida do preenchimento restante da cavidade com resina composta fotopolimerizável;

1.4 com resina composta fotopolimerizável, utilizando como base um cimento de ionômero de vidro fotopolimerizável;

2) Estudar a infiltração marginal presente na união resina composta autopolimerizável/resina composta fotopolimerizável. 
4. MATERIAIS E MÉTODOS 


\section{MATERIAIS E MÉTODOS}

\subsection{Considerações Gerais}

Foram realizadas restaurações classe II "in vitro", nas faces proximais mesial e distal de 16 molares decíduos hígidos, com indicação de extração por motivos ortodônticos ou esfoliados. No total, 32 cavidades oclusoproximais (OM e OD) foram restauradas, correspondendo a 8 cavidades por grupo, de acordo com o material utilizado. Após serem restaurados, os dentes foram armazenados em água destilada por 24 horas, polidos e submetidos à ciclagem térmica, processo de impermeabilização, imersão em solução corante, inclusão em resina epóxi, seccionamento no sentido mésiodistal (3 cortes por amostra) e obtenção de fotomicrografias para avaliação. 


\subsection{Materiais}

\subsection{1 materiais restauradores}

Os materiais restauradores utilizados neste estudo encontram-se no quadro I, sendo constituído por 2 resinas compostas, 1 adesivo dentinário e 1 cimento de ionômero de vidro fotopolimerizável.

Quadro I - Materiais Restauradores

\begin{tabular}{|c|c|c|}
\hline NOME COMERCIAL & TIPO & FABRICANTE \\
\hline Z-100 & $\begin{array}{c}\text { Resina Composta } \\
\text { Fotopolimerizável }\end{array}$ & $3 \mathrm{M}$ \\
\hline BIS-FILL 2B & $\begin{array}{c}\text { Resina Composta } \\
\text { Autopolimerizável }\end{array}$ & Bisco Inc. \\
\hline SCOTCHBOND & $\begin{array}{c}\text { Sistema Adesivo } \\
\text { Dentinário }\end{array}$ & $3 \mathrm{M}$ \\
\hline VITREMER & Ionômero de Vidro \\
Restaurador & $3 \mathrm{M}$ \\
\hline
\end{tabular}

4.2.2 instrumental e dispositivos

Os instrumentais e dispositivos utilizados no processo restaurador e de acabamento estão listados a seguir:

a) Empregados diretamente no processo restaurador 
$\Rightarrow$ brocas carbide $\mathrm{n}^{\text {os }} 245$ e 330 ;

$\Rightarrow$ taça de borracha (SS White);

$\Rightarrow$ escovas de Robinson;

$\Rightarrow$ porta matriz Toflemire;

$\Rightarrow$ matriz de aço;

$\Rightarrow$ espátula Hollenback n 3 (Duflex- Inox Ind. e Com. Ltda. S. P.);

$\Rightarrow$ pincéis $\mathrm{n}^{\circ} 0$ (Tigre - S. P.);

$\Rightarrow$ sonda milimetrada.

b) Empregados no processo de acabamento

$\Rightarrow$ pontas diamantadas $\mathrm{n}^{\circ} 2135$ FF (KG Sorensen);

$\Rightarrow$ discos Sof-Lex (3M);

$\Rightarrow$ tiras de lixa abrasiva (3M).

4.2.3 material e instrumental para armazenamento, ciclagem térmica, impermeabilização, infiltração, inclusão, seccionamento e avaliação

a) Armazenamento e ciclagem térmica

$\Rightarrow$ água destilada;

$\Rightarrow$ potes plásticos.

b) Impermeabilização e imersão em solução corante 
$\Rightarrow$ resina epóxica araldite ultra-rápido (Brascola S. B. C. / S. P.);

$\Rightarrow$ espátulas de madeira e bloco de papel plastificado;

$\Rightarrow$ esmalte de unha (Colorama - CEIL Com. Exp. Ind. LTDA);

$\Rightarrow$ nitrato de prata a $50 \%$ (solução aquosa).

c) Inclusão e seccionamento

$\Rightarrow$ resigel líquido (DIFIBRA Com. de Prod. P/ Fiberglass LTDA);

$\Rightarrow$ mangueira plástica;

$\Rightarrow$ espátulas de madeira;

$\Rightarrow$ recipientes plásticos;

$\Rightarrow$ placa de acrílico.

d) Avaliação

$\Rightarrow$ filmes Kodacolor - Kodak Gold Plus - 35 mm, 36 poses (Kodak Bras. Com. Ind. LTDA).

4.2.4 equipamento

$$
\begin{aligned}
& \Rightarrow \text { caneta de alta rotação (Extra-Torque - Kavo); } \\
& \Rightarrow \text { micro-motor (baixa-rotação - Kavo); } \\
& \Rightarrow \text { paquímetro digital (Mitutoyo Co. - Japão); } \\
& \Rightarrow \text { aparelho fotopolimerizador (Optilux } 150 \text { - Demetron/Kerr Co.); }
\end{aligned}
$$


$\Rightarrow$ aparelho para ciclagem térmica - Ética Engenharia LTDA Disciplina de Odontopediatria da F. O. U. S. P. ;

$\Rightarrow$ aparelho para seccionamento LabCut - Extec - Disciplina de Dentística da F. O. U. S. P. ;

$\Rightarrow$ Sistema Fotomicrográfico Olympus PM-20 (Olimpus America Inc. USA/Micronal S.A.) - Disciplina de Dentística da F. O. U.S.P.

\subsection{Métodos}

\subsection{1 amostra}

Selecionou-se 16 dentes molares decíduos, com indicação de extração por motivos ortodônticos ou esfoliados, hígidos, os quais foram armazenados em solução fisiológica até a sua utilização. Procurou-se selecionar dentes com volume coronário relativamente próximos para que, após o preparo, as cavidades proximais apresentassem tamanhos aproximados. Foram divididos em 4 grupos de 4 dentes cada, de acordo com os fatores de variação introduzidos, a saber:

GRUPO 1 : Scotchbond Multi-Adesão Plus + Z-100;

GRUPO 2 : Scotchbond Multi-Adesão Plus + Bis-Fill 2B; 
GRUPO 3 : Scotchbond Multi-Adesão Plus + Bis-Fill 2B + Z-100;

GRUPO 4 : Vitremer + Scotchbond Multi-Adesão Plus + Z-100.

\subsection{2 limpeza e preparo cavitário}

Os dentes foram limpos com pedra-pomes e água, com o auxílio de escovas de Robinson montadas em contra-ângulo e micro-motor.

Em cada dente, confeccionou-se 2 preparos cavitários oclusoproximais (OM e OD) com brocas carbide de $n^{\text {os }} 245$ e 330 em alta-rotação, com as seguintes dimensões: largura vestíbulo-lingual, $2 \mathrm{~mm}$; altura da caixa proximal, $3 \mathrm{~mm}$ e profundidade da caixa proximal, $2 \mathrm{~mm}$. Em todas as caixas proximais, a parede gengival localizava-se em esmalte.

As medidas foram realizadas com o auxílio de um paquímetro digital, com o intuito de se uniformizar as cavidades. As paredes cavitárias obedeceram às seguintes configurações: paredes vestibulares e linguais da caixa oclusal paralelas entre si e perpendiculares à parede pulpar; parede pulpar plana e paredes vestibulares e linguais da caixa proximal convergentes para oclusal e divergentes para proximal; caixa axial arredondada com a concavidade voltada para a polpa; parede gengival arredondada. Todos os ângulos diedros e triedros arredondados.

Os instrumentos cortantes rotatórios foram substituídos a cada grupo de 4 dentes preparados. Após o término dos preparos, as cavidades foram lavadas com um detergente (tergentol), em seguida com água destilada e secas com jatos de ar. 


\subsection{3 procedimento restaurador}

Antes de se iniciar os procedimentos restauradores, os dentes foram divididos, em grupos, aleatoriamente.

\subsubsection{1 colocação da matriz}

Após o preparo cavitário, procedeu-se a colocação da matriz de aço (5 mm), montada em um porta-matriz tipo Toflemire.

\subsubsection{2 condicionamento ácido e aplicação do adesivo}

Com o auxílio de uma pinça clínica, segurou-se uma bolinha de algodão embebida em ácido fosfórico a $35 \%$ e condicionou-se toda a cavidade durante 15 segundos. Os dentes foram lavados com água e secos por igual período de tempo.

Em seguida, procedeu-se a aplicação do primer e adesivo utilizandose um pincel, e fotopolimerizou-se o adesivo por 20 segundos.

\subsubsection{3 técnicas de restauração}

Grupo 1: Utilizou-se a resina composta fotopolimerizável Z-100 (3M). Ela foi colocada utilizando-se a técnica vertical ou lateral, ou seja, camadas 
no sentido vestíbulo-lingual, com cada uma delas sendo polimerizadas durante 40 segundos (Donly et al.,1987; Imparato, 1996).

Grupo 2: Nesse grupo, o material utilizado foi a resina composta Bis-Fill 2B (Bisco Inc.), autopolimerizável. O material foi manipulado em porções iguais, sendo inserido em porção única.

Grupo 3: Colocou-se, na caixa proximal, uma camada de $1 \mathrm{~mm}$ de resina composta autopolimerizável (Bis-Fill 2B, Bisco Inc.). Antes do endurecimento completo dessa camada de resina, inseriu-se uma camada da resina composta fotopolimerizável (Z-100, 3M), condensando-a levemente, e aguardou-se a polimerização por completo da primeira camada. Somente após a completa polimerização da resina Bis-Fill 2B é que se polimerizou a primeira camada da resina composta Z-100, preenchendose o restante da cavidade com resina composta fotopolimerizável (Z-100, 3M), em camadas no sentido vestíbulo-lingual, sendo cada uma delas polimerizada por 40 segundos (Bertolotti, 1991).

Grupo 4: Inicialmente, colocou-se uma pequena camada de cimento de ionômero de vidro (Vitremer, 3M), ao nível da junção amelo-dentinária, a qual foi polimerizada por 40 segundos. Preencheu-se o restante da cavidade com resina composta fotopolimerizável $(Z-100,3 M)$, através da técnica vertical, sendo cada camada polimerizada por 40 segundos. 
4.3.3.4 acabamento e polimento das restaurações

Concluída a restauração, a matriz foi retirada e procedeu-se ao acabamento e polimento. Inicialmente, os excessos mais grosseiros foram retirados com pontas diamantadas, série extrafina (K.G. Sorensen) $\quad n^{0}$ 2135 FF. O próximo passo foi o armazenamento das amostras em água destilada por 24 horas, e somente após esse período é que se concluiu o acabamento e polimento. Os excessos menores, das faces proximais, foram removidos com discos Sof-Lex (3M). Devido aos cuidados no processo restaurador, os excessos proximais foram retirados com tiras de lixa de óxido de alumínio (3M).

Decorrido esse período, os dentes foram limpos com spray ar/água e armazenados em recipientes plásticos contendo água destilada à temperatura ambiente, por um período de 1 semana para que a resina composta sofresse expansão através da sorção de água (Miranda Júnior, 1994), a fim de proporcionar uma maior homogeneização das mesmas.

\subsubsection{5 ciclagem térmica}

Este procedimento teve por finalidade simular as condições do ambiente oral, provocando o "envelhecimento" da restauração, por diferenças nos valores dos coeficientes de expansão térmica da estrutura dental e dos materiais restauradores. 
A ciclagem térmica foi realizada em um aparelho específico no laboratório da Disciplina de Odontopediatria do Departamento de Ortodontia e Odontopediatria da Faculdade de Odontologia da Universidade de São Paulo, desenvolvido pela Ética Engenharia Ltda. (Figura 1).

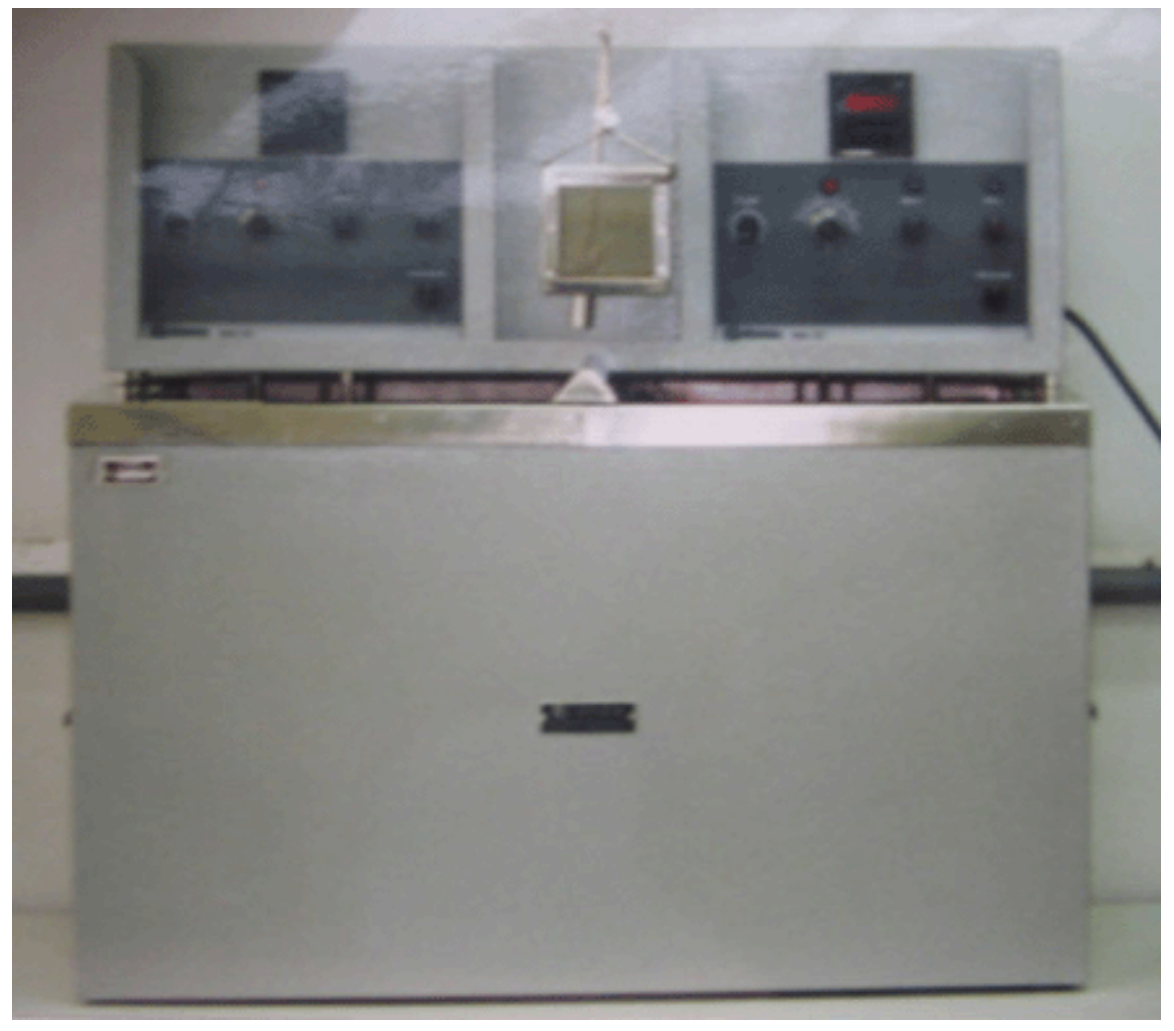

Figura 1 - Máquina de ciclagem térmica

Esta máquina consiste de dois reservatórios para água, com aproximadamente 20 litros cada um, cujas temperaturas são diferentes (frio e quente). A regulagem da temperatura se dá de forma eletrônica, com termostato de precisão de $0,1^{\circ} \mathrm{C}$. Apresenta um timer para o controle do tempo de imersão em cada banho. É constituída ainda de uma parte mecânica na qual está fixada uma haste, cuja extremidade contém um 
recipiente metálico no qual são colocadas as amostras. O translado desta haste permite alternar automaticamente de um banho para outro, de acordo com a programação preestabelecida quanto ao tempo de duração de cada banho e o número de ciclos.

O processo de ciclagem térmica utilizado neste trabalho foi de 700 ciclos, nas temperaturas entre $5^{\circ} \mathrm{C}$ e $55^{\circ} \mathrm{C}$, com tempo de 60 segundos em cada banho, e intervalos de 3 segundos entre os banhos como definido por Miranda Júnior, 1994.

4.3.3.6 impermeabilização e imersão em solução corante

Após a ciclagem térmica, iniciou-se o processo de impermeabilização das superfícies radicular e coronária.

A porção radicular, quando presente, foi recoberta com 2 camadas de resina epóxica de rápida polimerização (Araldite ultra-rápida), seguida de 2 camadas de esmalte de unha.

A porção coronária foi impermeabilizada com 2 camadas de esmalte de unha, deixando-se uma "janela" de aproximadamente $1 \mathrm{~mm}^{2}$, localizada na face proximal, compreendendo a interface dente $\mathrm{x}$ restauração da parede gengival, exposta à ação do corante e interface da resina composta auto e fotopolimerizável.

Os dentes foram imersos em solução corante de nitrato e prata a $50 \%$, durante 8 horas, mantidos armazenados em um recipiente plástico escuro. Em seguida, foram lavados em água corrente durante 10 minutos e 
expostos a lâmpada fluorescente por um período de 8 horas (Wu \& Cobb, 1981; Wu et al., 1983; Miranda Jr. \& Bussadori, 1995). Esse procedimento foi realizado para revelar o nitrato de prata que é incolor em solução.

\subsubsection{7 inclusão das amostras}

Esta etapa consistiu da inclusão dos dentes em resina epóxi, os quais foram acondicionados em um pedaço de mangueira plástica, com aproximadamente $2 \mathrm{~cm}$ de comprimento por $1,8 \mathrm{~cm}$ de largura, a fim de proporcionar um maior volume de resina, facilitando a preensão pela máquina.

\subsubsection{8 seccionamento das amostras}

Após a montagem da amostra em uma máquina LabCut, fabricada pela Extec, e provida de um disco diamantado de alta concentração, procedeu-se aos cortes das amostras no sentido mésio-distal. Foram obtidos

3 cortes de $1 \mathrm{~mm}$, das faces, mesial e distal, totalizando 6 superfícies a serem avaliadas por amostra.

\subsubsection{9 obtenção das fotomicrografias}

Obtidos os cortes, iniciou-se o processo de montagem das amostras no microscópio para a obtenção das fotomicrografias. Foi utilizada uma 
máquina Olympus, montada em um sistema fotomicrográfico Olympus PM-20, com 1x de aumento, e filmes Kodacolor ASA 100. Foram feitas fotomicrografias das interfaces dente/material restaurador das amostras. Obteve-se fotografias em tamanho $10 \times 15$, a fim de facilitar a avaliação pelos examinadores.

4.3.3.10 avaliação quantitativa do grau de penetração do corante

Três avaliadores, previamente treinados, analisaram as fotomicrografias e atribuíram escores às paredes gengival e axial, que variaram segundo escala em que os valores aumentavam de acordo com o maior grau de infiltração.

Escala de Infiltração

0 - nenhuma infiltração marginal presente;

1 - infiltração apenas em esmalte;

2 - infiltração em 1/3 da parede gengival em dentina;

3 - infiltração em 2/3 da parede gengival em dentina;

4 - infiltração em toda a extensão da parede gengival, atingindo a parede axial ou difusão em direção à polpa. 


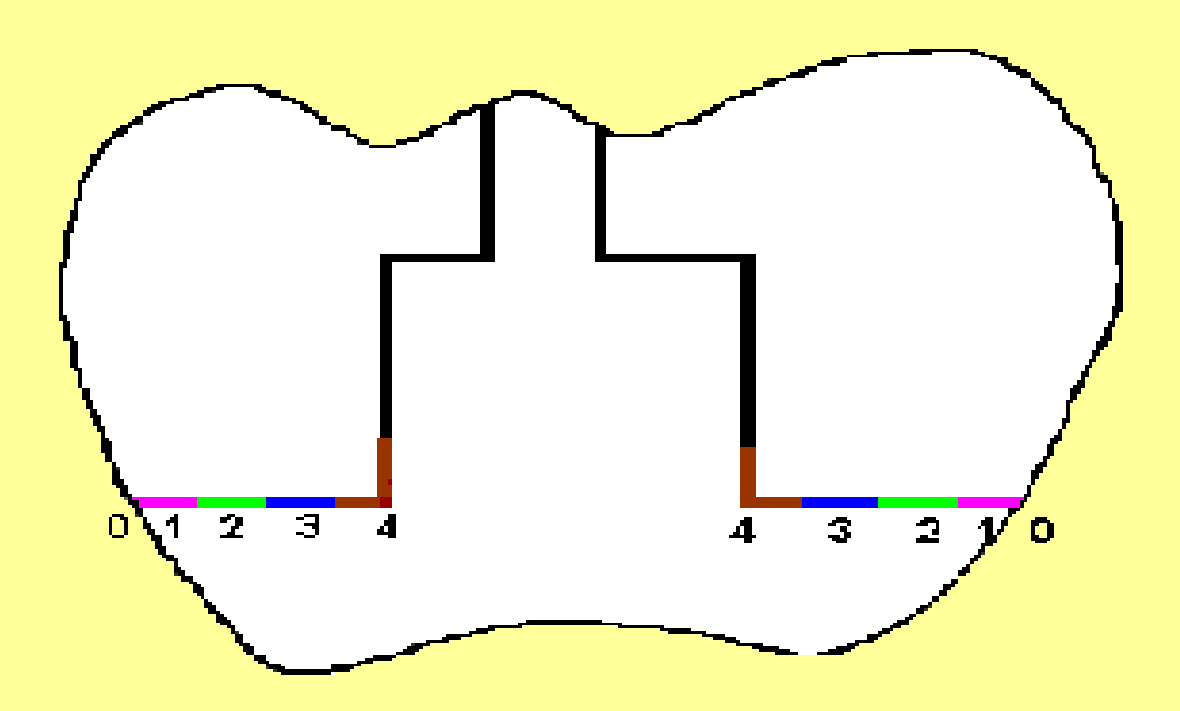

Figura 2 - Escala de avaliação (graus de infiltração): 0 = nenhuma infiltração; 1 = infiltração em esmalte; 2 = infiltração em $1 / 3$ da parede gengival em dentina; $3=$ infiltração em 2/3 da parede gengival em dentina; 4 = infiltração em toda a extensão da parede gengival, atingindo a parede axial ou difusão em direção à polpa

Avaliou-se 3 cortes de cada restauração, atribuindo-se os escores às faces mesial e distal.

4.3.3.11 avaliação da interface resina composta autopolimerizável/resina composta fotopolimerizável.

Nesta etapa, procurou-se avaliar a infiltração ocorrida na interface resina composta autopolimerizável/resina composta fotopolimerizável (grupo 3). Foram avaliadas 8 restaurações (OM e OD), sendo 3 cortes de cada amostra, totalizando 24 superfícies avaliadas. 
5. RESULTADOS 


\section{RESULTADOS}

\subsection{Resultados}

5.1.1 microinfiltração quanto à técnica restauradora

Os quatro grupos de restaurações foram avaliados: Grupo 1: Z-100 (Figura 3); Grupo 2: Bis-Fill 2B (Figura 4); Grupo 3: Bis-Fill 2B/Z-100 (Figura 5) e Grupo 4: lonômero/Z-100 (Figura 6).

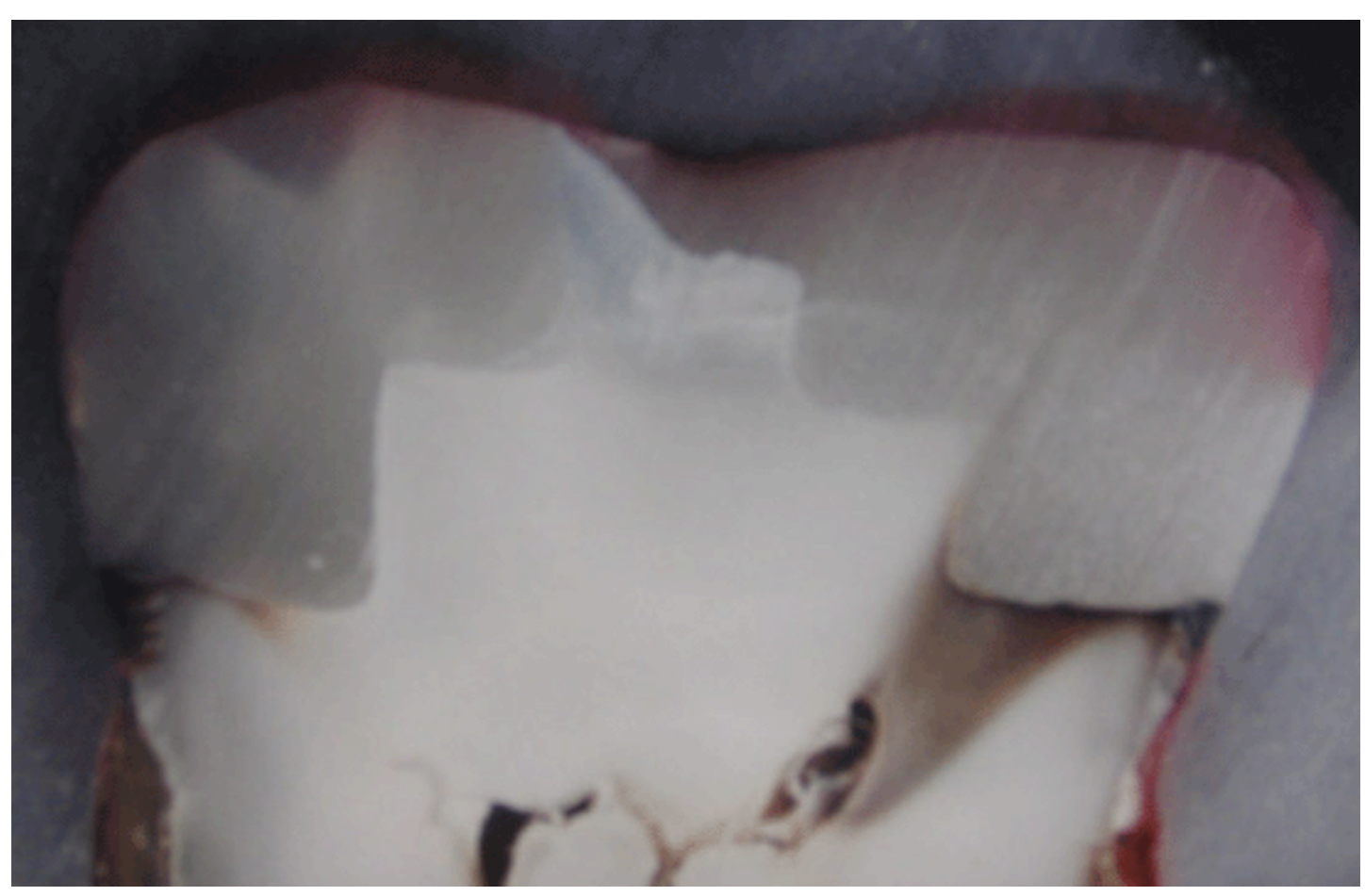

.Figura 3 - Penetração do corante em amostra do grupo 1 (Z-100) 


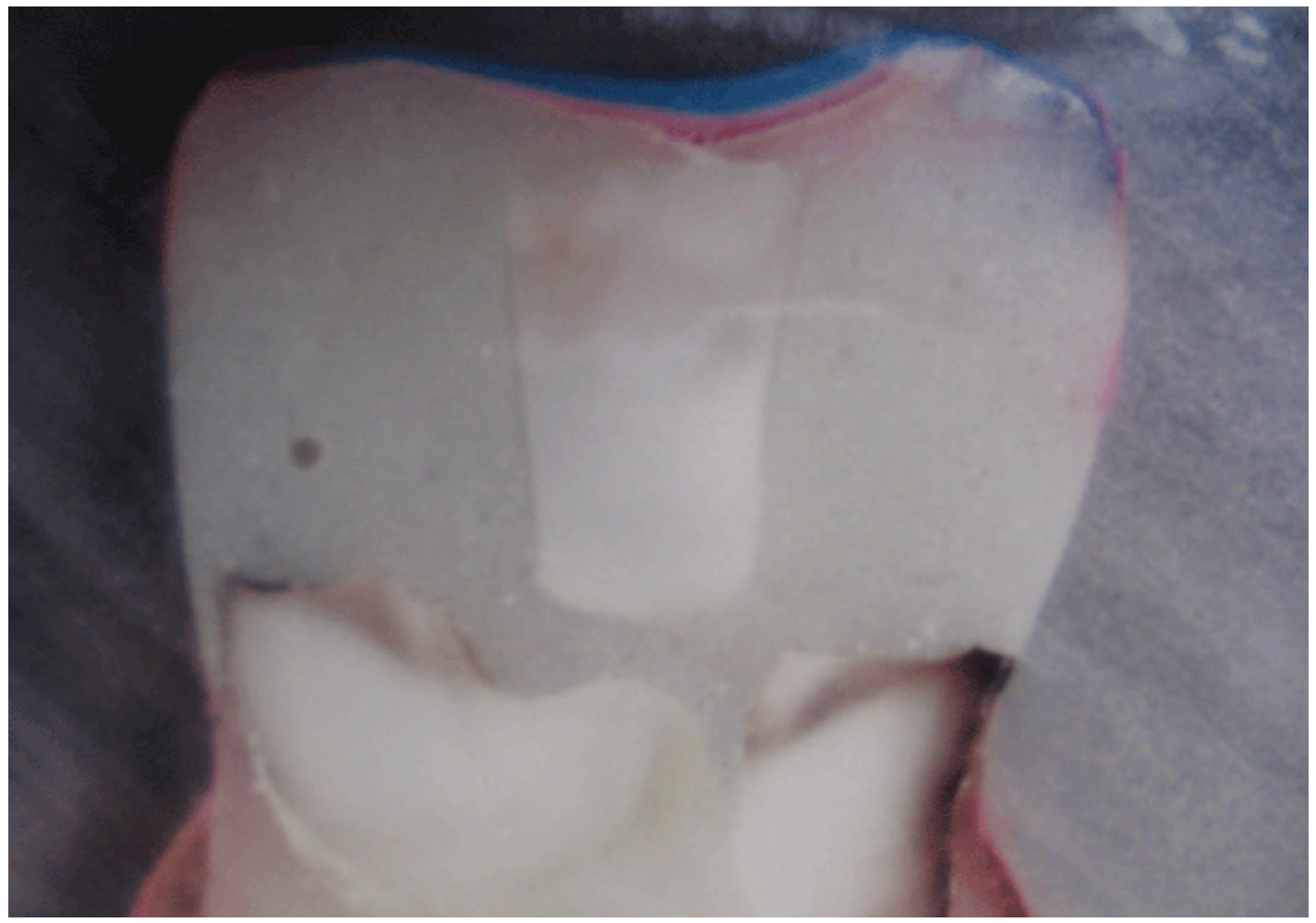

Figura 4 - Penetração do corante em amostra do grupo 2 (Bis-Fill 2B)

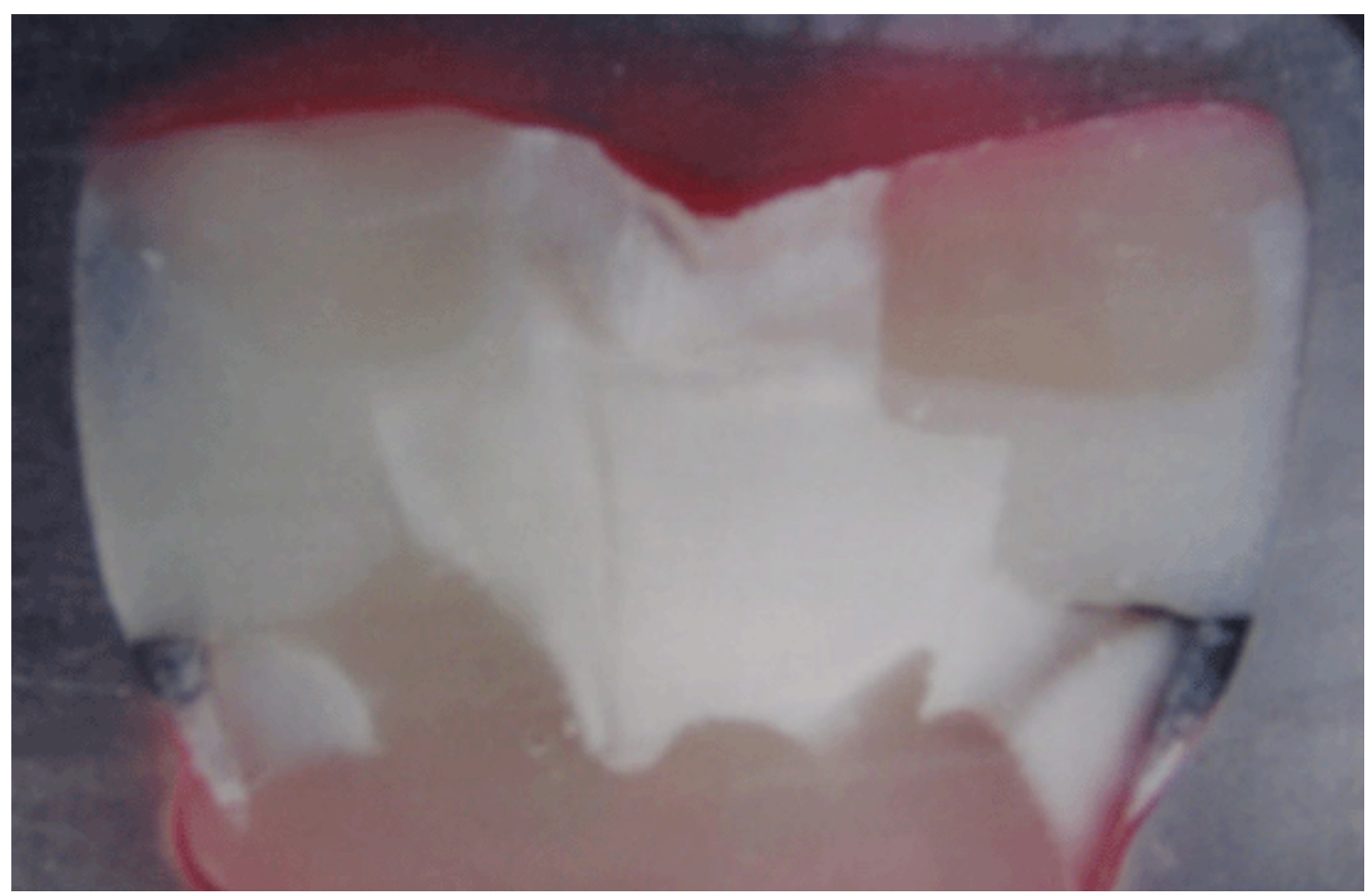

Figura 5 - Penetração do corante em amostra do grupo 3 (técnica mista resina composta autopolimerizável/fotopolimerizável) 


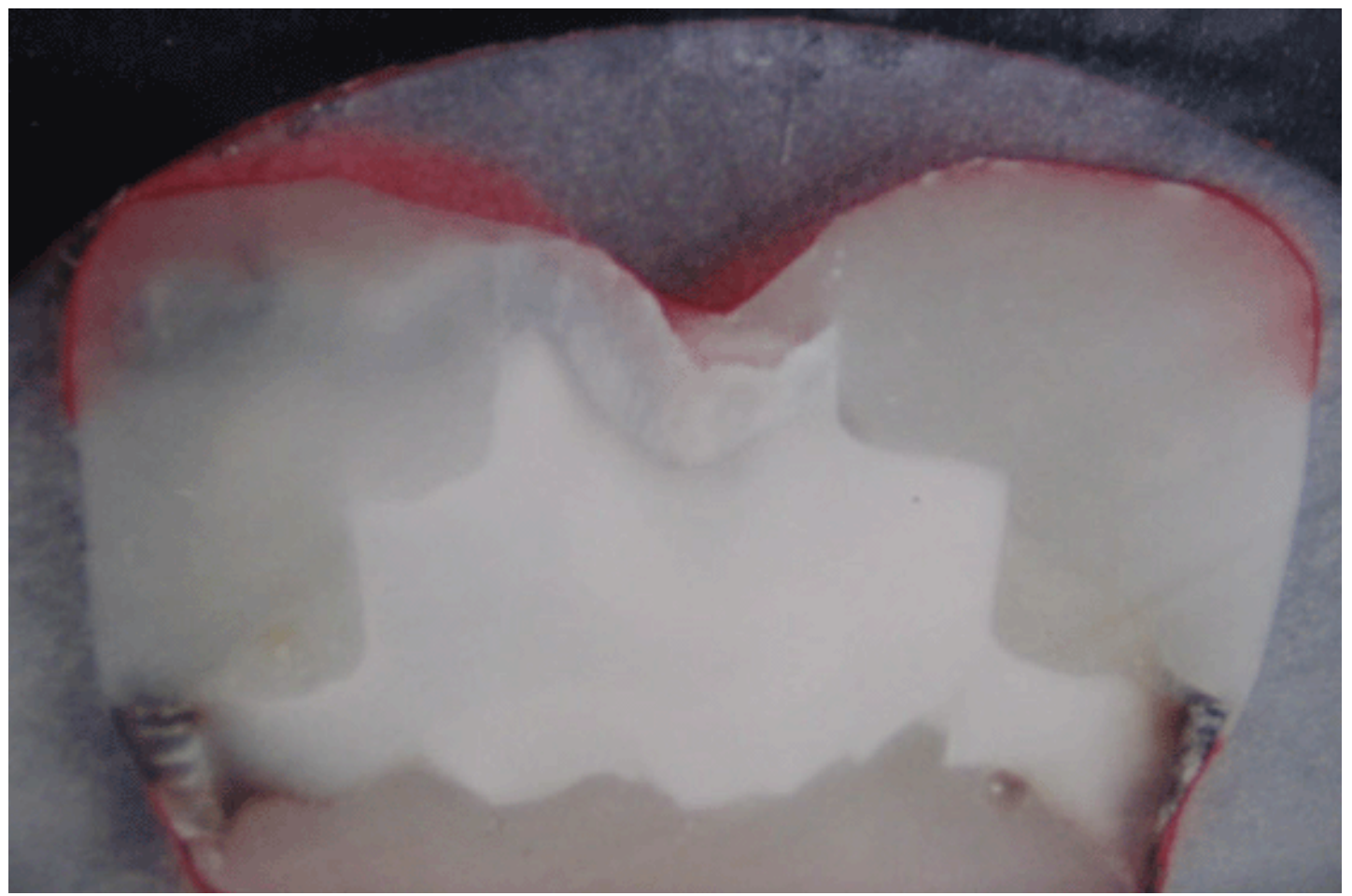

Figura 6 - Penetração do corante em amostra do grupo 4 (cimento de ionômero de vidro/resina composta fotopolimerizável)

Para cada grupo, realizou-se 8 repetições (corpos-de-prova) que puderam ser observadas. Para cada restauração, 3 secções foram avaliadas. A tabela 5.1 apresenta os graus de infiltração observados nos referidos grupos. 
TABELA 5.1 - Graus de infiltração marginal referentes aos quatro grupos

\begin{tabular}{|c|c|c|c|c|c|c|c|c|c|c|c|c|}
\hline $\begin{array}{c}\text { Corpos-de- } \\
\text { Prova }\end{array}$ & \multicolumn{3}{|c|}{ Z-100 } & \multicolumn{3}{|c|}{ BIS-FILL 2B } & \multicolumn{3}{|c|}{$\begin{array}{c}\text { BIS-FILL 2B/ } \\
\text { Z-100 }\end{array}$} & \multicolumn{3}{|c|}{$\begin{array}{c}\text { IONÔMERO/ } \\
\text { Z-100 }\end{array}$} \\
\hline 1 & 3 & 3 & 3 & 1 & 2 & 1 & 2 & 2 & 2 & 2 & 1 & 3 \\
\hline 2 & 3 & 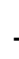 & 3 & 4 & 4 & 4 & 2 & 2 & 2 & 1 & 1 & 3 \\
\hline 3 & 3 & . & 2 & 2 & 2 & 2 & 2 & - & 3 & 1 & 1 & 1 \\
\hline 4 & 3 & 3 & 2 & 1 & 1 & 1 & 1 & 1 & 1 & 4 & 4 & 4 \\
\hline 5 & 4 & 2 & 3 & 3 & 2 & 0 & 2 & 3 & 3 & 3 & 1 & 1 \\
\hline 6 & 4 & 3 & 4 & 4 & 3 & 2 & 3 & 3 & 3 & 3 & 2 & 3 \\
\hline 7 & 3 & 3 & 3 & 3 & 3 & 3 & 1 & 1 & 2 & 2 & 2 & 2 \\
\hline 8 & 3 & 3 & 3 & 4 & 3 & 4 & 2 & 2 & 0 & 2 & 1 & 2 \\
\hline
\end{tabular}

Os valores correspondentes aos índices de infiltração observados foram submetidos à análise estatística, com o auxílio de um software GMC, versão 7.0, desenvolvido pelo Prof. Dr. Geraldo Maia Campos da Faculdade de Odontologia de Ribeirão Preto - USP. Foi utilizado o teste de KruskalWallis (teste não paramétrico). Os resultados desse teste mostraram haver diferença estatisticamente significante ao nível de $5 \%$ entre os grupos (Valor $(H)=17.87$ ). Este teste utilizou os dados transformados em postos (tabela $5.2)$. 
TABELA 5.2 - Dados originais transformados em postos e a respectiva média entre os grupos

\begin{tabular}{|c|c|c|c|c|}
\hline $\begin{array}{c}\text { Corpos-de- } \\
\text { Prova }\end{array}$ & $Z-100$ & BIS-FILL 2B & $\begin{array}{c}\text { BIS-FILL 2B/ } \\
\text { Z-100 }\end{array}$ & $\begin{array}{c}\text { IONÔMEROI } \\
\text { Z-100 }\end{array}$ \\
\hline 1 & $64,0 \quad 64,0 \quad 64,0$ & $\begin{array}{lll}12,0 & 34,5 & 12,0\end{array}$ & $34,534,5 \quad 34,5$ & $34,5 \quad 12,0 \quad 64,0$ \\
\hline 2 & $64,0-64,0$ & $87,087,0 \quad 87,0$ & $34,5 \quad 34,5 \quad 34,5$ & $12,0 \quad 12,0 \quad 64,0$ \\
\hline 3 & $64,0-34,5$ & $34,5 \quad 34,5 \quad 34,5$ & $34,5-64,0$ & $\begin{array}{lll}12,0 & 12,0 & 12,0\end{array}$ \\
\hline 4 & $64,0 \quad 64,0 \quad 34,5$ & $12,012,0 \quad 12,0$ & $12,0 \quad 12,0 \quad 12,0$ & $87,0 \quad 87,0 \quad 87,0$ \\
\hline 5 & $87,0 \quad 87,0 \quad 64,0$ & $64,0 \quad 34,5 \quad 1,0$ & $34,5 \quad 64,0 \quad 64,0$ & $\begin{array}{lll}64,0 & 12,0 & 12,0\end{array}$ \\
\hline 6 & $87,0 \quad 64,0 \quad 87,0$ & $87,0 \quad 64,0 \quad 34,5$ & $64,0 \quad 64,0 \quad 64,0$ & $64,0 \quad 34,5 \quad 64,0$ \\
\hline 7 & $64,0 \quad 64,0 \quad 64,0$ & $64,0 \quad 64,0 \quad 64,0$ & $12,0 \quad 12,0 \quad 34,5$ & $34,5 \quad 34,5 \quad 34,5$ \\
\hline 8 & $64,0 \quad 64,0 \quad 64,0$ & $87,0 \quad 64,0 \quad 87,0$ & $34,5 \quad 34,5 \quad 1,0$ & $\begin{array}{lll}34,5 & 12,0 & 34,5\end{array}$ \\
\hline Médias & 65,50 & 48,91 & 35,84 & 38,77 \\
\hline
\end{tabular}

Em seguida, os grupos foram comparados 2 a 2 pelas médias dos postos para verificar entre quais destes havia diferenças (tabela 5.3). Por meio dessa comparação, pôde-se verificar que não houve diferença estatisticamente significante quanto à infiltração marginal, entre os grupos Bis-Fill 2B, Bis-Fill 2B/Z-100 e lonômero/Z-100; e que a diferença entre o grupo Z-100 e os demais foram significante ao nível de 5\%. 
TABELA 5.3 - Comparação entre as médias dos postos dos quatro grupos e significância

\begin{tabular}{c|c|c}
\hline Amostras Comparadas & $\begin{array}{c}\text { Diferenças Entre as } \\
\text { Médias dos Postos }\end{array}$ & Significância \\
\hline \hline Z-100 x Bis-Fill 2B & 16,59 & $*$ \\
\hline Z-100 x Bis-Fill 2B/Z-100 & 29,66 & $*$ \\
\hline Z-100 x lonômero/Z-100 & 26,73 & n.s. \\
\hline Bis-Fill 2B x Bis-Fill 2B/Z-100 & 13,07 & n.s. \\
\hline Bis-Fill 2B x lonômero/Z-100 & 10,14 & n.s. \\
\hline Bis-Fill 2B/Z-100 x lonômero/Z-100 & 2,93 & \\
\hline
\end{tabular}

-* Estatisticamente significante $(\alpha<0,05)$

- n.s. = não significante

5.1.2 microinfiltração na interface resina composta autopolimerizável/resina composta fotopolimerizável

Foi avaliado a interface resina composta autopolimerizável/ fotopolimerizável, presente no grupo 3 (Bis-Fill 2B/Z-100), em um total de 8 corpos de prova. O grau de infiltração encontrado em todos os cortes foi 0 (zero) (Figura 7). Portanto, não houve penetração do corante em nenhuma das amostras. 


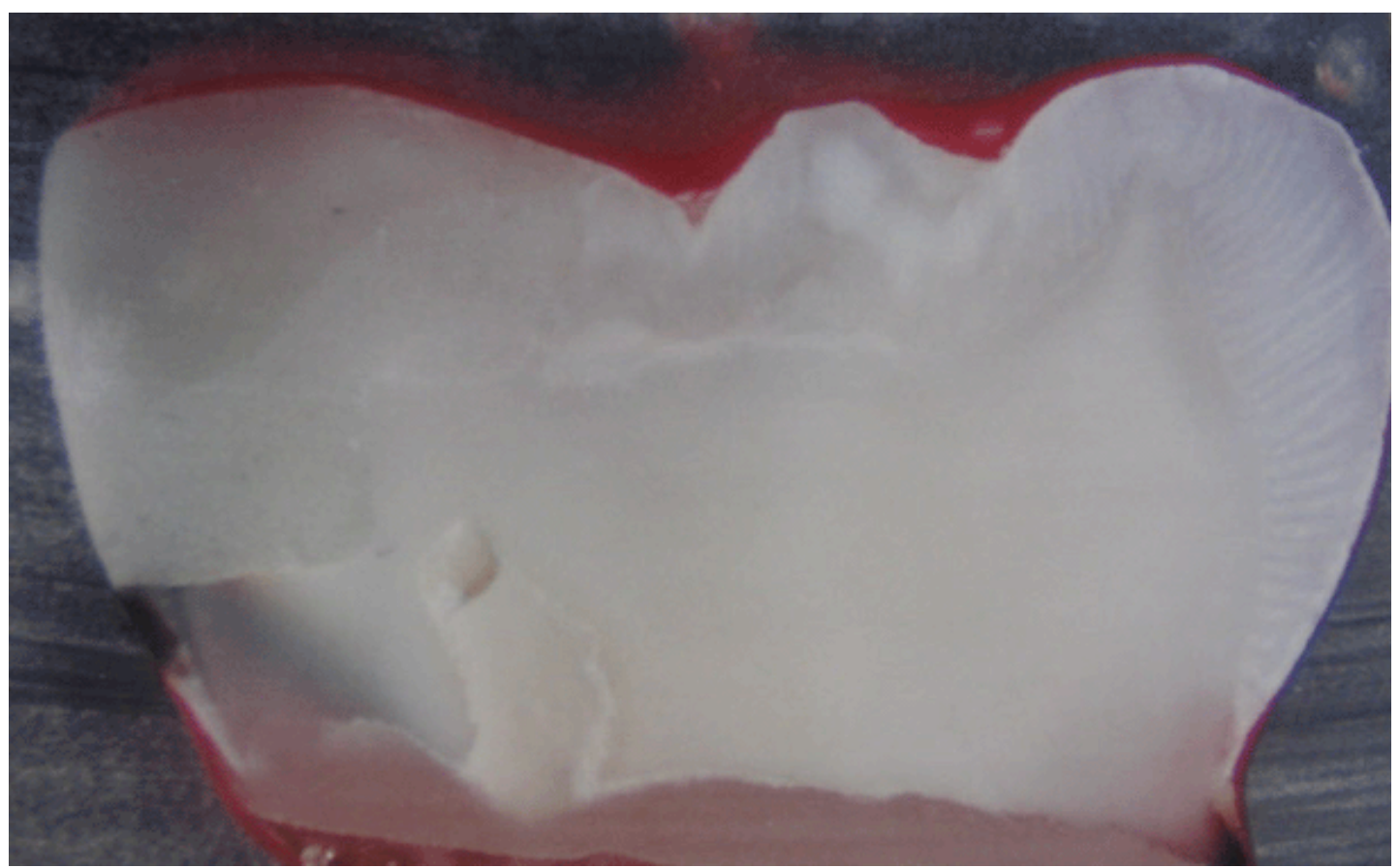

Figura 7 - Interface resina composta autopolimerizável/ fotopolimerizável 


\section{DISCUSSÃO}




\section{DISCUSSÃO}

Inúmeros estudos têm relatado observações sobre as resinas compostas, especialmente quando utilizadas em restaurações classe II de dentes decíduos (Leifler \& Varpio, 1981; Garcia-Godoy, 1984; Varpio, 1985; Donly \& Jensen, 1986; Holan et al., 1986; Vann Jr. et al., 1986a; Vann Jr. et al., 1986b; Donly et al., 1987; Oldenburg et al., 1987a; Donly et al., 1988; Fisbein et al., 1988; Eidelman et al., 1989; Guelmann et al., 1989; Fuks et al., 1990b; Nicole Filho et al., 1990; Varpio et al., 1990; Barr-Agholme et al., 1991; Vieira, 1991; Ciamponi, 1992; Holan et al., 1992; Sperb et al., 1993; Reid et al., 1994; Miranda Jr. \& Bussadori, 1995; Imparato, 1996).

Contudo, a infiltração marginal é uma das principais deficiências apresentadas pelas restaurações classe II em resina composta (Marquez et al., 1990; Vieira, 1991; Ciamponi, 1992; Holan et al., 1992; Sperb et al., 1993; Reid et al., 1994; Imparato, 1996). Essa infiltração ocorre principalmente na parede gengival da caixa proximal, decorrente de uma deficiente adaptação do material (Fisbein et al., 1988; Holan et al., 1992).

Até o presente, não se dispõe de resinas compostas livres da contração de polimerização e com um coeficiente de expansão térmica semelhante ao dos tecidos dentários, o que permitiria a confecção de 
restaurações perfeitamente adaptadas e seladas (Lutz et al., 1986; Vieira, 1991).

A presença e o tamanho das fendas existentes entre a resina e as paredes cavitárias estão diretamente relacionadas com uma combinação de vários fatores, dentre os quais: má adaptação do material às paredes cavitárias, contração de polimerização, absorção de água, margens de esmalte finas, dificuldade na condensação e técnica de inserção (Eidelman et al., 1989; Fuks et al., 1990a; Fuks et al., 1990b; Vieira, 1991).

Essas fendas podem ser minimizadas utilizando uma resina composta "condensável" e uma técnica de inserção correta (Nicole Filho et al., 1990; Varpio et al., 1990; Barr-Agholme et al., 1991; Vieira, 1991; Ciamponi, 1992; Holan et al., 1992; Sperb et al., 1993; Reid et al., 1994; Miranda Jr. \& Bussadori, 1995; Imparato, 1996).

Segundo Lutz et al., 1986, a qualidade marginal das restaurações em resina composta pode ser substancialmente aumentada através do direcionamento dos vetores de contração. De acordo com Pollack, 1987, existe um vetor mais forte de contração nas resinas compostas fotopolimerizáveis do que nas autopolimerizáveis.

A aplicação de um adesivo como alternativa de se minimizar a microinfiltração foi defendida por vários autores (Fisbein et al., 1988; Vieira, 1991; Holan et al., 1992; Imparato, 1996). Por estarmos de acordo com a opinião anteriormente citada, utilizamos o adesivo em todos os grupos experimentais, o que está em concordância com a maior parte dos trabalhos. Entretanto, mesmo utilizando um adesivo, observamos que a microinfiltração 
não foi totalmente eliminada, mas, sim, minimizada de acordo com o material restaurador empregado.

Todavia, Varpio, 1985, contrapondo-se a essa tendência, relata que a não utilização de um agente de união não parece influenciar a proporção de sucesso das restaurações próximo-oclusais de molares decíduos. Porém, o autor concorda que a aplicação do adesivo é o caminho mais fácil para assegurar a efetividade do condicionamento ácido.

A fim de se avaliar esta microinfiltração, inúmeras técnicas foram desenvolvidas. A penetração de substâncias corantes é difusa e falha em evidenciar uma penetração mais acurada do contraste. Atualmente, segundo os achados de Wu et al., 1983, o método de coloração com prata mostra que a infiltração marginal pode estar mais profunda do que quando avaliada com outros métodos.

Com base no trabalho acima mencionado, e em outros desenvolvidos por Wu \& Cobb, 1981; Miranda Jr. \& Bussadori, 1995; adotamos o método de coloração com o nitrato de prata a $50 \%$ diferindo dos estudos realizados até o presente momento, nos quais outra solução corante foi utilizada (Holan et al., 1986; Fisbein et al., 1988; Guelmann et al., 1989; Vieira, 1991; Sperb et al., 1993; Reid et al., 1994; Imparato, 1996).

Um problema inerente que limitaria o sucesso com a utilização de resinas compostas fotopolimerizáveis em preparos cavitários classe II é a contração de polimerização do material (Bertolotti, 1991; Vieira, 1991; Fusayama, 1992; Fusayama, 1993; Sperb et al., 1993). Essa contração estaria em torno de 2,0 a 3,2\% (Lutz et al., 1986). 
A fotopolimerização das resinas compostas, com luz visível, resulta, inicialmente, em uma polimerização da superfície oclusal, resultando em uma tendência em deslocar o material das margens do preparo cavitário, com a polimerização prosseguindo em direção à camada inicialmente colocada, como continuidade do processo (Pollack, 1987; Hinoura et al., 1988; Bertolotti, 1991; Fusayama, 1992; Fusayama, 1993).

Contrário ao comportamento das resinas fotopolimerizáveis, as autopolimerizáveis iniciam sua polimerização nas áreas mais profundas do preparo cavitário (Bertolotti, 1991; Fusayama, 1992; Fusayama, 1993).

A resina composta autopolimerizável, quando utilizada em restaurações classe II em dentes decíduos apresentou resultados satisfatórios (Mack, 1970; Nelson et al., 1979; Nelson et al., 1980; Tonn et al., 1980; Paquette et al., 1982; Garcia-Godoy, 1984; Roberts et al., 1985; Varpio, 1985; Holan et al., 1986; Varpio et al., 1990).

Quando da utilização de uma resina composta autopolimerizável, observa-se, microscopicamente, maior quantidade de porosidades internas presentes nessas resinas comparada às fotopolimerizáveis, porosidades estas que podem ser atribuídas ao processo necessário para a incorporação das duas diferentes pastas (Leinfelder \& Vann Jr., 1982; Bertolotti, 1991; Fusayama, 1992; Fusayama, 1993).

Muitos autores detectaram que as resinas compostas fotopolimerizáveis também apresentaram bons resultados quando da sua utilização em cavidades classe II de dentes decíduos (Oldenburg et al., 1985; Tonn \& Ryge, 1985; Donly \& Jensen, 1986; Donly et al., 1987; 
Oldenburg et al., 1987a; Fisbein et al., 1988; Tonn \& Ryge, 1988; Eidelman et al., 1989; Fuks et al., 1990a; Marquez et al., 1990; Nicole Filho et al., 1990; Barr-Agholme et al., 1991; Vieira, 1991; Ciamponi, 1992; Holan et al., 1992; Ostlund et al., 1992; Imparato, 1996). Entretanto, ao se analisar a microinfiltração, os resultados são contraditórios (Miranda Jr. \& Bussadori, 1995; Imparato, 1996)

Ao compararmos o desempenho quanto à microinfiltração da resina composta autopolimerizável à fotopolimerizável quando utilizada isoladamente na restauração de cavidades classe II em dentes decíduos, encontramos diferenças significantes, o que vêm a contrastar com os achados de Paquette et al., 1983; Richardson \& Derkson, 1987, que apresentaram bons resultados clínicos de ambos os materiais.

Outro fator que poderia atuar minimizando a microinfiltração é a técnica que utiliza uma base de cimento de ionômero de vidro sob a resina composta. Técnica esta, conhecida com "técnica do sanduíche" (Guelmann et al., 1989; Vieira, 1991; Fusayama, 1992; Sperb et al., 1993; Reid et al., 1994).

O uso de uma base de ionômero de vidro apresenta várias propriedades clínicas positivas, dentre as quais destacamos: a adesão à estrutura dentária, coeficiente de expansão térmica próximo ao do dente, radiopacidade e a liberação de flúor (Lutz et al., 1986; Donly et al., 1988; Vieira, 1991; Sperb et al., 1993).

Em nosso estudo, um dos grupos foi restaurado de acordo com essa técnica, sendo a base de ionômero aplicada até a junção amelo-dentinária. 
Os resultados encontrados demonstraram que, mesmo não sendo totalmente eficiente quanto à eliminação da microinfiltração, apresentou bom desempenho quanto à limitação da penetração do corante. Tal fato, está de acordo com os estudos de Lutz et al., 1986; Guelmann et al., 1989; Vieira, 1991; Sperb et al., 1993; Reid et al., 1994; Miranda Jr. \& Bussadori, 1995.

Quanto à técnica de inserção do material, inúmeras foram propostas como método de se diminuir a contração de polimerização, melhorar a adaptação marginal e conseqüente microinfiltração (Donly \& Jensen, 1986; Lutz et al., 1986; Donly et al., 1987; Bertolotti, 1991; Imparato, 1996).

Dentre essas, a mais indicada é a técnica de inserção vertical, relatada por Donly \& Jensen, 1986; Donly et al., 1987; Marquez et al., 1990; Holan et al., 1992; e corroborada por Imparato, 1996. Baseado nesses relatos, esta foi a técnica por nós adotada neste estudo.

A técnica alternativa não descrita em estudos anteriores utilizando dentes decíduos e adotada nesse trabalho foi a técnica que associa resina composta autopolimerizável à fotopolimerizável, ou seja, a técnica mista citada por Bertolotti, 1991; Fusayama, 1992; Fusayama, 1993; Garberoglio et al., 1995, em dentes permanentes.

Dentre as principais vantagens dessa técnica, Bertolotti, 1991, destaca: aumento da adaptação marginal, menor sensibilidade pósoperatória, menor tempo de trabalho e melhor obtenção dos contatos proximais.

De acordo com Bertolotti, 1991; Fusayama, 1992, a razão pela qual essa técnica deva melhorar o selamento marginal está relacionada com o 
iniciador químico do adesivo que acelerará a polimerização da resina quimicamente ativada em contato com o próprio adesivo. A polimerização da resina composta estará direcionada para a parede cavitária e potencialmente conterá a tendência do material contrair em direção ao centro da massa (Garberoglio et al., 1995).

Esta tendência em polimerização em direção ao dente é melhorada pela tendência das resinas quimicamente ativadas começarem a polimerizarse na porção mais quente do preparo, conhecida como interface denterestauração (Bertolotti, 1991; Fusayama, 1992; Fusayama, 1993; Garberoglio et al., 1995). Entretanto, por termos trabalhado "in vitro", esse fator de variação não pode ter influenciado.

Neste trabalho, a utilização da técnica mista, ou seja, a que associa a resina autopolimerizável à fotopolimerizável, resultou em um menor grau de microinfiltração, quando comparado aos demais grupos, estando, portanto, coincidindo com os resultados obtidos por Bertolotti, 1991; Garberoglio et al., 1995.

Ao procurarmos avaliar a microinfiltração ocorrida na interface resina composta autopolimerizável/fotopolimerizável observamos que nenhuma microinfiltração foi observada nessa interface, nos dentes em que foi utilizado a técnica mista. Em nenhum dos trabalhos pesquisados, nos quais procurou se avaliar a microinfiltração em restaurações que utilizaram a técnica mista (Bertolotti, 1991; Fusayama, 1992; Fusayama, 1993; Garberoglio et al., 1995) foi feita alguma menção a esse fato. Acreditamos 
que esse fato se deve principalmente à adesão química entre ambas as resinas compostas.

Por conseguinte, recomendamos quando da utilização de resina composta na restauração de cavidades classe II de molares decíduos, a técnica que associe resina composta autopolimerizável à fotopolimerizável, seguida da colocação de resina fotopolimerizável segundo à técnica mista, ou da colocação de uma base de ionômero de vidro sob a restauração de resina composta, através da técnica de inserção vertical.

Com esses resultados, de microinfiltração, pode-se supor que a resina composta, independente do tipo ou da técnica utilizada, apresenta contração de polimerização (fato esse inerente ao próprio material), o que leva à formação de fendas, que não impede por completo a microinfiltração. Essas fendas podem ser menores, com a utilização de uma base de cimento de ionômero de vidro ou de uma camada de resina autopolimerizável na parede gengival.

Finalmente, esse estudo "in vitro" dá apenas uma indicação de prováveis ocorrências sob condições clínicas, não fornecendo, porém, informações sobre os possíveis efeitos do stress oclusal mecânico. 


\section{CONCLUSÕES}




\section{CONCLUSÕES}

Com base na metodologia empregada e nos resultados obtidos, concluiu-se que:

1. Os quatro grupos (resina composta fotopolimerizável; resina composta autopolimerizável; misto - resina composta auto e fotopolimerizável e ionômero/resina composta fotopolimerizável) apresentaram microinfiltração em graus variados;

2. Os grupos que utilizaram a técnica mista e o cimento de ionômero de vidro, respectivamente grupos 3 e 4 , apresentaram os menores graus de infiltração quando comparados aos grupos 1 e 2;

3. Não foi observada microinfiltração na interface resina composta autopolimerizável/resina composta fotopolimerizável. 
REFERÊNCIAS BIBLIOGRÁFICAS 


\section{REFERÊNCIAS BIBLIOGRÁFICAS*}

1. BARR-AGHOLME, M.; ODÉN, A.; DAHLLOF, G.; MODEÉR, T. A twoyear clinical study of light-cured composite and amalgam restorations in primary molars. Dent Mater, v.7, n.4, p.230-233, Oct. 1991.

2. BERTOLOTTI, R. L. Posterior composite technique utilizing directed polymerization shrinkage and a novel matrix. Pract Period Aesthet Dent, v.3, n.4, p.53-58, June/July 1991.

3. CIAMPONI, A. L. Avaliação do desempenho clínico de restaurações de resina composta em molares decíduos: dois anos de acompanhamento. São Paulo, 1992. 121 p. Dissertação (Mestrado em Odontopediatria) - Faculdade de Odontologia da Universidade de São Paulo.

* De acordo com NBR-6023 da Associação Brasileira de Normas Técnicas, 1989. Abreviatura de periódicos segundo "Index to Dental Literature". 
4. DERKSON, G. D.; RICHARDSON, A. S. Clinical evaluation of posterior composite resin restorations: three year results. J Dent Res, v.65, p.814, 1986. [Resumo n. 792]

5. DERKSON, G. D.; RICHARDSON, A. S.; WALDMAN, R. Clinical evaluation of composite resin and amalgam posterior restorations: two year results. J Can Dent Assoc, v.49, n.4, p.277-279, Apr. 1983.

6. DERKSON, G. D.; RICHARDSON, A. S. ; WALDMAN, R. Clinical evaluation of composite resin and amalgam posterior restorations: three year results. J Can Dent Assoc, v.50, n.6, p.478-480, June/July 1984 .

7. DILLEY, D. H.; OLDENBURG, T. R.; VANN Jr., W. F. A comparison of composite and amalgam restorations: three year results. J Dent Res, v.66, p.166, Mar. 1987. [Resumo n. 478]

8. DILLEY, D. H.; CRISP, R. M.; OLDENBURG, T. R.; VANN Jr., W. F. Time required for placement of alloy versus resin posterior restorations. J Dent Res, v.64, p.350, Mar. 1985. [Resumo n. 1583] 
9. DONLY, K. J.; JENSEN, M . E. Posterior composite polymerization shrinkage in primary teeth: an in vitro comparison of three techniques. Pediatr Dent, v.8, n.3, p.209-212, Sept. 1986.

10. DONLY, K. J.; WILD, T.; JENSEN, M. E. Cuspal reinforcement in primary teeth: an in vitro comparison of three restorative materials. Pediatr Dent, v.10, n.2, p. 102-104, June 1988.

11. DONLY, K. J.; WILD, T. W.; JENSEN, M. E. Posterior composite class II restorations: in vitro comparison of preparation designs and restoration techniques. Dent Mater, v.6, n.2, p.88-93, Apr. 1990.

12. DONLY, K. J.; JENSEN, M. E.; REINHARDT, J.; WALKER, J. D. Posterior composite polymerization shrinkage in primary teeth: an in vivo comparison of three restorative techniques. Pediatr Dent, v.9, n.1, p.22-25, Mar. 1987.

13. EIDELMAN, E.; FUKS, A.; CHOSACK, A. A clinical radiographic an SEM evaluation of class 2 composite restorations in primary teeth. Operat Dent, v.14, n.2, p. 58-63, Spring 1989. 
14. FISBEIN, S.; HOLAN, G.; GRAJOWER, R.; FUKS, A. The effect of VLC scotchbond and an incremental filling technique on leakage around class II composite restorations. J Dent Child, v.55, n.1, p.29-33, Jan./Feb. 1988.

15. FUKS, A. B.; CHOSACK, A.; EIDELMAN, E. Assessment of marginal leakage around class II composite restorations in retrieved primary molars. Pediatr Dent, v.12, n.1, p.24-26, Feb. 1990a.

16. FUKS, A. B.; CHOSACK, A.; EIDELMAN, E. A two-year evaluation in vivo and in vitro of class 2 composites. Operat Dent, v.15, n.6, p.219-223, Nov./Dec. 1990b.

17. FUSAYAMA, T. Biologic problems of the light-cured composite resin. Quintessence Int, v.24, n.4, p.225-226, Apr. 1993.

18. FUSAYAMA, T. Indications for self-cured and light-cured adhesive composite resins. J Prosthet Dent, v.67, n.1, p.46-51, Jan. 1992.

19. GARBEROGLIO, R.; COLI, P.; BRANNSTROM, M. Contraction gaps in class II restorations with self-cured and light-cured resin composites. Am J Dent, v. 8, n. 6, p. 303-307, Dec. 1995. 
20. GARCIA-GODOY, F. Clinical evaluation of a posterior composite in class II restorations in primary molars: one year results. Acta Odontol Pediatr, v.5, n.1, p.9-11, June 1984.

21. GUELMANN, M.; FUKS, A.; HOLAN, G.; GRAJOWER, R. Marginal leakage of class II glass-ionomer-silver restorations with and without posterior composite coverage: an in vitro study. J Dent Child, v.56, n.4, p.277-282, July/Aug. 1989.

22. HINOURA, K.; SETCOS, J. C.; PHILLIPS, R. W. Cavity design and placement techniques for class 2 composites. Operat Dent, v.13, n.1, p.12-19, Winter 1988.

23. HOLAN, G.; CHOSACK, A.; CASAMASSIMO, P. S.; EIDELMAN, E. Marginal leakage of impregnated class 2 composites in primary molars: an in vivo study. Operat Dent, v.17, n.4, p.122-128, July/Aug. 1992.

24. HOLAN, G.; FUKS, A.; GRAJOWER, R.; CHOSACK, A. In vitro assesment of the effect of scotchbond on the marginal leakage of class II composite restorations in primary molars. J Dent Child, v.53, n.3, p.188-192, May/June 1986.

25. IMPARATO, J. C. P. Avaliação da microinfiltração de quatro técnicas restauradoras com resina composta nas caixas 
proximais em cavidades classe II de molares decíduos. São Paulo, 1996. 93 p. Dissertação (Mestrado em Odontopediatria) Faculdade de Odontologia da Universidade de São Paulo.

26. LEINFELDER, K. F.; VANN Jr., W. F. The use of composite resins in primary molars. Pediatr Dent, v.4, n.1, p.27-31, Mar. 1982.

27. LEIFLER, E.; VARPIO, M. Proximoclusal composite restorations in primary molars: a two-year follow-up. J Dent Child, v.48, n.6, p.411-416, Nov/ Dec. 1981.

28. LUTZ, F.; KREJCI, I.; OLDENBURG, T. R. Elimination of polymerization stresses at the margins of posterior composite resin restorations: a new restorative technique. Quintessence Int, v.17, n.12, p.777-787, Dec. 1986.

29. MACK, E. A restorative pedodontic practice without amalgam. J Dent Child, v.37, n.5, p.428-434, Sept./Oct. 1970.

30. MARQUEZ, M. I. G.; RODRIGUEZ, E. G.; NUNEZ, M. M. Problemas clínicos de microinfiltración de materiales restaurativos en morates temporales. Rev Actual Odontoestomatol Esp, v.50, n.397, p. 31-34, oct. 1990. 
31. MATHEWSON, R. J.; RETZIAFF, A. E.; PORTER, D. R. Marginal failure of amalgam in deciduous teeth: a two year report. J Am Dent Assoc, v.88, n.1, p. 134-136, Jan. 1974.

32. MIRANDA JÚNIOR, W. G. Avaliação "in vitro" da infiltração nas caixas proximais de pré-molares humanos restaurados com diferentes adesivos universais e resinas compostas. São Paulo, 1994. 92 p. Tese (Doutorado em Materiais Dentários) Faculdade de Odontologia da Universidade de São Paulo.

33. MIRANDA Jr., W. G.; BUSSADORI, S. K. Avaliação da infiltração em restaurações combinadas em dentes posteriores. In: REUNIÃO ANUAL DA SOCIEDADE BRASILEIRA DE PESQUISAS ODONTOLÓGICAS, Águas de São Pedro, 1995. Anais ... Águas de São Pedro: SBPqO, 1995. p. 35. [Resumo n.70]

34. MORRIS, M. E.; BARKIN, P. R.; SOELBERG, K. B.; WEIS, R. W. Complex primary molar restorations using a composite resin (a 42month study using amalgam as comparative material). J Calif Dent Assoc, v.7, n.2, p.39-42, Feb. 1979. 
35. NELSON, G. V.; OSBORNE, E. N.; PHILLIPS, R. W. Amalgam versus composite resin in class $\|$ restorations in primary teeth. $\mathbf{J}$ Dent Res, v.58, p.327, 1979. [Resumo n. 943]

36. NELSON, G. V.; OSBORNE, J. W.; GALE, E. N.; NORMAN, R. D.; PHILLIPS, R. W. A three-year clinical evaluation of composite resin and a high copper amalgam in posterior primary teeth. $\mathbf{J}$ Dent Child, v.47, n.6, p.414-418, Nov./Dec. 1980.

37. NICOLE FILHO, W. D.; PEAKE, F. L.; ANDRADE, J. L. R. Resina composta fotopolimerizável associada ao adesivo de dentina fotopolimerizável: resposta ao seu uso em decíduos posteriores. Rev Bras Odontol, v.47, n.2, p. 22-28, mar./abr. 1990.

38. OLDENBURG, T. R,; VANN Jr., W. F.; DILLEY, D. C. Comparison of composite and amalgam in posterior teeth of children. Dent Mater, v.3, n.4, p.182-186, Aug. 1987a.

39. OldENBURG, T. R,; VANN Jr., W. F.; DILLEY, D. C. Composite restorations for primary molars: results after four years. Pediatr Dent, v.9, n.2, p. 136-143, July 1987b. 
40. OldENBURG, T. R.; VANN Jr., W. F.; DILLEY, D. C. Composite restorations for primary molars: two-year results. Pediatr Dent, v.7, n.2, p.96-103, June 1985.

41. OLDENBURG, T.; VANN Jr., W. F.; DILLEY, D. Use of composite resins in primary molars: one year results. J Dent Res, v.63, p.277, 1984. [Resumo n. 954]

42. OSTLUND, J.; MÖLLER, K.; KOCH, G. Amalgam, composite resin and glass ionomer cement in class II restorations in primary molars - a three year clinical evaluation. Swed Dent J, v.16, n.3, p.81-86, 1992.

43. PAQUETTE, D.; VANN Jr. , W. F.; OLDENBURG, T.; LEINFELDER, K. Modified cavity preparations for composites in primary molars teeth. J Dent Res, v.61, p.270, 1982. [Resumo n. 827]

44. PAQUETTE, D. E.; VANN Jr., W. F.; OldENBURG, T. R.; LEINFELDER, K. F. Modified cavity preparation for composite resins in primary molars. Pediatr Dent, v.5, n.4, p.246-251, Dec. 1983 
45. POLLACK, B. F. Class II composites: 1987 thoughts and techniques. NY State Dent J, v.53, n.5, p.25-27, May 1987.

46. REID, J. S.; SAUNDERS, W. P.; SHARKEY, S. W.; WILLIAN, C. An in vitro investigation of microleakage and gap size of glass ionomer/composite resin "sandwich" restorations in primary teeth. J Dent Child, v.61, n.4, p.225-259, July/Aug. 1994.

47. RICHARDSON, A. S.; DERKSON, G. D. Clinical evaluation of lightcured and auto cured composite resin restorations. J Can Dent Assoc, v.53, n.9, p.681-683, Sept. 1987.

48. ROBERTS, M.; MOFFA, J. P.; BRORING, C. L. Two year clinical evaluation of a proprietary composite resin for the restoration of primary posterior teeth. Pediatr Dent, v. 7, n.1, p.14-18, Mar. 1985.

49. SHEY, Z.; OPPENHEIM, M. A clinical evaluation of a radiopaque material in the restoration of anterior and posterior teeth. $\mathbf{J} \mathbf{A m}$ Dent Assoc, v.98, n.4, p.569-571, Apr. 1979.

50. SPERB, J. P. B.; RODRIGUES, R. M. A.; ARAÚJO, F. B.; CONCEIÇÃO, E. N. O efeito do condicionamento ácido da base de cimento de ionômero de vidro na microinfiltração de 
restaurações de classe II com resina composta em dentes decíduos. Rev Odontopediatr Atual Clín, v.1, n.2, p.17-23, jan./mar. 1993.

51. TONN, E.; RYGE, G. Clinical evaluations of composite resin restorations in primary molars: a four-year follow-up study. J Am Dent Assoc, v.117, n.5, p.603-606, Oct. 1988.

52. TONN, E. M.; RYGE, G. Two-year clinical evaluation of light-cured composite resin restoration in primary molars. J Am Dent Assoc, v. 111, n.1, p.44-48, July 1985 .

53. TONN, E. M.; RYGE, G.; CHAMBERS, D. W. A two year clinical study of a carvable composite resin used as class II restorations in primary molars. J Dent Child, v.47, n.6, p.405-418, Nov. 1980.

54. VANN Jr., W. F.; BARKMEIER, W. W.; MAHLER, D. B. Assessing composite resin wear in primary molars: four year findings. J Dent Res, v.67, n.5, p.876-879, May 1988.

55. VANN Jr., W. F.; OLDENBURG, R. C.; DILLEY, D. C. Composite restorations for primary molar: three year results. J Dent Res, v.65, p.813, 1986a. [Resumo n. 791] 
56. VANN Jr, W. F.; BARKMEIER, W. W.; OLDENBURG, T. R.; LEINFELDER, K. F. Quantitative wear assessment for composite restorations in a primary molars. Pediatr Dent, v.8,n.1, p.7-10, Mar. 1986b.

57. VARPIO, M. Proximoclusal composite restorations in primary molars: a six-year follow-up. J Dent Child, v.52, n.6, p.435-440, Nov./Dec. 1985.

58. VARPIO, M.; WARFRINGE, J.; NORÉN, J. G. Proximo-occlusal composite restorations in primary molars: marginal adaptation, bacterial penetration and pulpal reactions. Acta Odontol Scand, v.48, n.3, p.161-167, June 1990.

59. VIEIRA, R. S. Avaliação “in vitro" da infiltração marginal de restaurações classe II, com resina composta fotoativada, em molares decíduos. São Paulo, 1991. 208 p. Tese (Doutorado em Odontopediatria) - Faculdade de Odontologia da Universidade de São Paulo.

60. WENDELL, J. J.; VANN Jr., W. F. Wear of composite resin restorations in primary versus permanent molar teeth. J Dent Res, v.67, n.1, p.71-74, Jan. 1988. 
61. WU, W.; COBB, E. N. A silver staining technique for investigating wear of restorative dental composites. J Biomed Mater Res, v.15, n.3, p.343-348, May 1981.

62. WU, W.; COBB, E.; DERMANN, K.; RUPP, N. W. Detecting margin leakage of dental composite restorations. J Biomed Mater Res, v.17, n.1, p.37-43, Jan. 1983. 
SUMMARY 


\section{SUMMARY}

\section{ANALYSIS “IN VITRO” OF MICROLEAKINGS ON GUM’S EDGES OF THE APPROXIMAL BOXES IN CLASS II CAVITIES OF DECIDUOUS MOLARS, RESTORED WITH AUTO AND LIGHT-CURED COMPOSITE RESIN}

The purpose of this study was evaluation "in vitro" of marginal microleakings, present on gum's edges of class II cavities of deciduous molars, restored with composite resin (auto and light-cured), with the use of a staining solution to verify the leaking. Cavities prepared presented enamel on gum's edges and were restored according to four different techniques: lightcured composite resin; auto-cured composite resin; mixed technique (auto and light-cured composite resin) and glass-ionomer/composite resin. Next, we proceeded to thermo-cycling $\left(5^{\circ} \mathrm{C}\right.$ and $55^{\circ} \mathrm{C}, 700$ cycles $)$, turning impermeable, immersion in staining solution and slicing. The microleaking evaluation was done according to a pre-established scale (from 0 a 4 degrees). After the statical analysis of the results, it was concluded that all the groups presented microleaking, in varying degrees. However, the groups which used the mixed technique and light-cured resin presented the smallest levels of leaking, and microleaking was not observed on the auto-cured composite resin/light-cured composite resin edge. 
Autorizo a reprodução pelos interessados.

\section{Alessandro Leite Cavalcanti}

São Paulo, 07 de Novembro de 1997. 